\title{
LA HABITACIÓN SAGRADA DE LA CIUDAD IBÉRICA DE LA SERRETA
}

\author{
POR \\ IGNACIO GRAU \\ Área de Arqueología. Universidad de Alicante \\ RICARDO OLMOS \\ Escuela Española de Historia y Arqueología en Roma. CSIC \\ ALICIA PEREA \\ Instituto de Historia. Centro de Ciencias Humanas y Sociales. CSIC
}

\section{RESUMEN}

En el siguiente artículo se analiza un departamento con probables funciones sagradas en el asentamiento ibérico de $\mathrm{La}$ Serreta (Alcoi-Cocentaina-Penàguila, Alicante). En esta habitación se recuperó un excepcional conjunto material que incluye algunos de los mejores ejemplos de cerámica con decoración figurada de estilo narrativo, una plaqueta de terracota que representa una divinidad nutricia, vajilla de importación e instrumental especializado de orfebre. Las características de este destacado conjunto nos llevan a definir el espacio como un depósito singular y una habitación representativa con posibles funciones religiosas que contribuiría a articular las complejas relaciones sociales y políticas del oppidum ibérico a finales del s. III a.C.

\section{SUMMARY}

In this paper a department with probable sacred functions in the Iberian settlement of La Serreta (Alcoi-CocentainaPenàguila, Alicante) is analyzed. In this room an exceptional material record was found that includes some of the better examples of the so-called narrative figured pottery style, the image of a nurse goddess in terracotta, imported vessels and specialized metal instruments. This outstanding ensemble allows us to define this space as a singular deposit and a representative room with possible religious functions, which formed the back bone of the complex social and political relationships of the Iberian oppidum at the end of the $3^{\text {rd }}$ cent. B.C.

PALABRAS CLAVE: Época Ibérica. Antigua Contestania. Prácticas religiosas. Prácticas artesanales. Orfebrería.

KEY WORDS: Iberian Iron Age. Ancient Contestania Region. Religious practices. Working techniques. Jewellery.

\section{INTRODUCCIÓN: LA DIVERSIDAD DE LAS PRÁCTICAS Y ESPACIOS RELIGIOSOS ENTRE LOS IBEROS ${ }^{1}$}

No cabe duda del importante avance producido en el conocimiento de los aspectos religiosos del mun-

${ }^{1}$ Trabajo realizado dentro de los proyectos de investigación, «La construcción de la naturaleza desde el poder: imáge- do ibérico en los últimos años. La proliferación de la actividad arqueológica de campo ha aportado nueva información con la que iluminar y revisar la documentación proveniente de antiguos trabajos. Pero no sólo se ha producido un importante acopio de evidencias, también han proliferado las propuestas de ordenación, clasificación y síntesis de los lugares religiosos y las prácticas que albergaron ${ }^{2}$. Estamos ante un paradigma abierto y por tanto fecundo y creativo.

La evaluación del objeto arqueológico, protagonista absoluto en los estudios pioneros, adquiere hoy un nuevo sentido al interrelacionarse con la información contextual, su asociación con otros elementos y su concreta ubicación en el espacio y el tiempo. Así la evaluación de las formas arquitectónicas y la ubicación de los lugares religiosos en la trama urbanís-

nes de la Grecia arcaica y de la cultura ibérica» (HUM200500213), «Romanización comparada: los casos de Ilici y Elo» (HUM2006-09874) patrocinados por la Dirección General de Universidades e Investigación, Ministerio de Ciencia e Innovación y Ajudes per a Equips Emergents 2007-GRE07-2P de la Universitat d'Alacant. El estudio relacionado con la matriz de bronce y el bloque de plomo se integra en el marco del Proyecto «Bases para una investigación arqueométrica y tecnómica sobre metalurgia en la Prehistoria y Antigüedad. La Península Ibérica» financiado por el Plan Nacional de I+D+I (HUM2006-06250) que dirige A. Perea dentro del más amplio Proyecto Au, desarrollado en el Instituto de Historia, CCHS, CSIC, Madrid. Agradecemos a D. Josep María Segura Martí, director del Museu Arqueològic Municipal Camil Visedo d'Alcoi, el permiso y todas las gestiones que nos facilitaron el análisis de los materiales arqueológicos. Las figuras 2, 4, 8, 9 y 10 han sido elaboradas a partir de dibujos de Emilio Cortell, Museu d'Alcoi; la figura 14 es de Sara Olmos.

${ }^{2} \mathrm{El}$ lector interesado encontrará las síntesis más recientes en el catálogo de la exposición Les Ibères (1997), 135-151, en el número monográfico dedicado a los espacios de culto del Quaderns d'Arqueologia i Prehistòria de Castelló, 18 (1997), o en los trabajos Moneo, T. (2003): Religio Ibérica. Santuarios, ritos y divinidades (siglos VII-I a.C.), Madrid y Olmos, R. (2004): «Imaginarios y prácticas religiosas entre los iberos. Perspectivas de un proceso histórico», Archiv für Religionsgeschichte, 6, 111-134, entre otros. 
tica o en el paisaje, hoy proporcionan importantes claves de comprensión de los espacios sacros. Recordemos al respecto que los más importantes intentos de clasificación de los lugares de culto toman como referencia su relación con las áreas de hábitat, con el tejido urbanístico y su interrelación con el paisaje natural. De ese modo se distinguen entre los espacios de culto vinculados a núcleos urbanos y aquellos emplazados en un entorno rural y varios asentamientos; dentro de esta horma se clasifican la variedad de espacios reconocidos. La bibliografía al respecto es amplia $^{3}$.

Tampoco debemos olvidar los importantes avances en el campo de la iconografía, especialmente a partir de su inmersión en el entorno mejor conocido de la imagen mediterránea y su sentido dentro del propio proceso de las sociedades ibéricas. Ha sido este un campo crucial en que se han logrado precisar los códigos de representación ideológica de las aristocracias ibéricas ${ }^{4}$.

Los avances descritos en estas gruesas pinceladas no pretenden más que mostrar a partir de mojones significativos el largo trecho recorrido en el conocimiento de la expresión religiosa ibérica. Pero también debemos hacer referencia a las cautelas con las que debemos movernos en un campo tan difícil como fascinante. Y ello nos lleva a reflexionar sobre algunos aspectos referidos a las posibilidades y limitaciones de la ar-

\footnotetext{
${ }^{3}$ Lucas, R. (1981): «Santuarios y dioses de la baja época ibérica». La Baja Época de la Cultura Ibérica. Actas de la Mesa Redonda celebrada en conmemoración del $10^{\circ}$ aniversario de la Asociación Española de Amigos de la Arqueología. Madrid, pp. 233-293; Prados, L. (1994): «Los santuarios ibéricos. Apuntes para el desarrollo de una arqueología del culto», Trabajos de Prehistoria 51, 1, pp. 129-140; Oliver, A. (1997): «La problemática de los lugares sacros en la historiografía arqueológica», Quaderns d'Arqueologia i Prehistòria de Castelló, 18, pp. 495-516; Bonet, H. y Mata, C. (1997): «Lugares de culto edetanos: Propuesta de definición», Quaderns de Prehistoria i Arqueologia de Castelló, 18, pp. 115-146; Domínguez Monedero, A. (1995): «Religión, rito y ritual durante la protohistoria peninsular. El fenómeno religioso en la Cultura Ibérica». Ritual, rites and religion in Prehistory. $3^{\text {rd }}$ Deya International Conference of Prehistory, II. BAR International Series, 611. Oxford, pp. 25-91; Domínguez Monedero, A. (1997): «Los lugares de culto en el mundo ibérico: espacio religioso y sociedad. Espacios y lugares cultuales en el mundo ibérico». Quaderns de Prehistòria i Arqueologia de Castelló, 18, pp. 391-404; Aranegui, C. (1995): «Iberia Sacra Loca. Sur le pas des Grees en Occident». Collection Etudes Massaliètes, 4, pp. 17-30; Almagro-Gorbea, M. y Moneo, T. (2000): Santuarios urbanos en el mundo ibérico. Bibliotheca Archaelogica Hispana, 4. Madrid; Moneo, T. (2003), cit. (n. 2).

${ }^{4}$ Olmos, R. (ed.) (1992): La sociedad ibérica a través de la imagen, Madrid; Olmos, R. (coord.) (1999): Los iberos y sus imágenes, CD-Rom, Madrid; Aranegui, C. (ed.), Mata, C. y Pérez, J. (1997): Damas y caballeros en la ciudad ibérica, Madrid.
}

queología, la principal forma de acercamiento a los aspectos religiosos de la sociedad ibérica.

En primer lugar, nuestros caminos de aproximación nos remiten a la materialidad de los cultos y prácticas religiosas que enfocamos desde el prisma mejor conocido de la religiosidad mediterránea. Nos situamos ante evidencias que se apartan de los contextos funcionales de uso doméstico o económico y que destacan por su carácter singular, su monumentalidad o su recurrencia. Son espacios y objetos que despuntan sobre las restantes evidencias por el cuidado en su realización material, la aparición recurrente de determinados tipos de objetos que denotan una deposición selectiva e intencional o la localización de conjuntos de objetos con nula funcionalidad práctica. Estas combinaciones, y otras posibles, no siempre son lo diáfanas y elocuentes que quisiéramos para reconstruir la actividad religiosa. De ese modo en ocasiones se habla de «espacios singulares» en los que se produce la intersección de los poderes políticos y religiosos, habida cuenta de la ligazón entre la esfera ideológica y del poder de las sociedades antiguas.

Las evidencias nos sitúan ante las prácticas religiosas de mayor visibilidad arqueológica, bien por lo destacado de su materialidad, bien por la frecuencia y reiteración de las actividades. Los bien conocidos santuarios étnico-territoriales fueron los primeros y principales sitios religiosos ibéricos en reconocerse precisamente por el acondicionamiento monumental de los lugares de culto o por la densa aparición de exvotos, en cualquiera de sus manifestaciones, de forma reiterada y repetitiva. Son las expresiones religiosas en las que intervienen un mayor número de participantes y atañen a la mayor parte de la comunidad, por lo que podríamos denominarlos «cultos oficiales». Más difícil es reconocer las prácticas religiosas más humildes que se escaparían de nuestros modos de aprehensión e interpretación.

Ante este panorama, debemos ser conscientes de las dificultades que se derivan del estudio de los espacios y prácticas religiosas. Los problemas no sólo emanan de la necesidad de mayor acopio de información y ejemplos, que sin duda contribuirán en el futuro a clarificar infinidad de aspectos, sino de la propia naturaleza del objeto de estudio. Habida cuenta del mosaico cultural ibérico, la heterogeneidad de la documentación y la propia versatilidad del fenómeno religioso, los intentos clasificatorios deben permanecer necesariamente abiertos. Pensamos que la búsqueda de símiles, paralelos o patrones a los que asociar los espacios que analizamos en cada caso concreto no debe constituirse como una norma rígida, más bien debe ser una inferencia débil. Con ello queremos ad- 


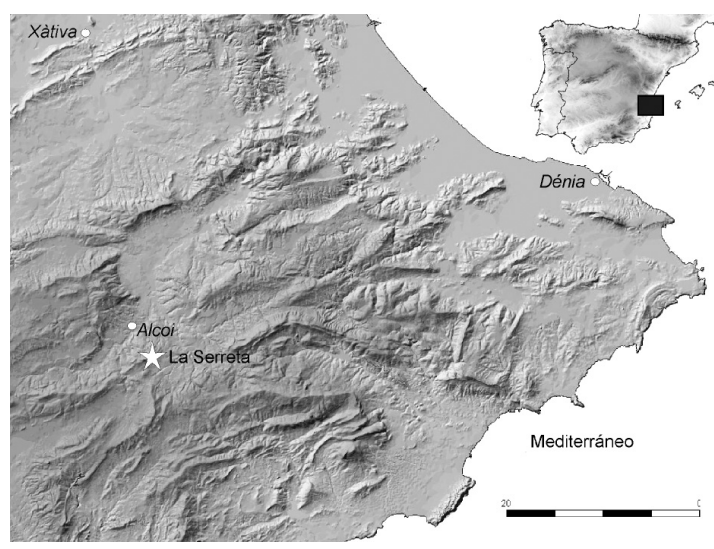

Fig. 1. Localización de la Serreta en el marco de la Contestania Ibérica.

vertir de forma preliminar que el estudio del espacio sacro que ahora iniciamos difícilmente encontrará un reflejo fiel en los lugares hoy conocidos. Como veremos, se asemejará a algunos lugares pero también encontraremos variaciones respecto a los espacios sacros conocidos del área oriental de Iberia con los que comparte un común marco sociocultural.

La habitación sagrada que ahora centra nuestra atención es un espacio integrado en la trama urbanística de la ciudad de La Serreta de Alcoi (Alcoi, Cocentaina, Penàguila; Alicante), el asentamiento principal de la región central de la Contestania en época clásica (Fig. 1). La Serreta es un conjunto arqueológico formado por un gran oppidum que cuenta con un santuario territorial y una necrópolis de la llamada época plena, es decir principalmente en los ss. IV y III a.C. Los recientes trabajos de caracterización del enclave y su papel en la organización del paisaje ibérico contestano han permitido reconocer la dinámica de ocupación del oppidum y su papel predominante en la organización del poblamiento en la región de Alcoi ${ }^{5}$.

\footnotetext{
${ }^{5}$ Por mor de la brevedad remitimos a los recientes trabajos publicados para la detallada caracterización del asentamiento y el territorio. Véase Llobregat Conesa, E. A., Cortell Pérez, E., Juan Moltó, J., Olcina Domenech, M. y Segura Martí, J.M. (1995): «El sistema defensiu de la porta d'entrada del poblat ibèric de La Serreta. Estudi preliminar». Recerques del Museu d'Alcoi, 4, pp. 135-162; Olcina Doménech, M., Grau Mira, I., Sala Sellés, F., Moltó Gisbert, S., Reig Seguí, C. y Segura Martí J. M. (1998): «Nuevas aportaciones a la evolución de la ciudad ibérica: el caso de La Serreta», en Aranegui, C. (ed.). Congreso Internacional Los Iberos, Príncipes de Occidente (Barcelona, marzo 1998). Barcelona, pp. 35-46. Olcina Doménech, M., Grau Mira, I. y Moltó Gisbert, S. (2000): «El sector I de la Serreta: noves perspectives al voltant de l'ocupació de l'assentament». Recerques del Museu d'Alcoi, 9, pp. 119144. Grau Mira, I. (2002): La organización del territorio en el área central de la Contestania Ibérica. Alicante; Idem, (2005), «El territorio septentrional de la Contestania», en Abad Casal, L.; Sala Sellés, F.; Grau Mira, I. (eds.) La Con-
}

Tras una primera etapa de ocupación correspondiente principalmente al s. IV a.C., durante el s. III a.C. se produce una ampliación de la ciudad a partir de la ocupación de las laderas meridionales del cerro en el que se ubica el oppidum. Posiblemente a fines de esta centuria o muy a inicios de la siguiente acaba de forma repentina la vida en el poblado y sus estancias y departamentos se sellaron con los ajuares en uso en el momento de su abandono. La recuperación y análisis arqueológico de estos conjuntos cerrados permiten reconocer la importancia del enclave a partir de sus evidencias materiales y reconocer la singularidad de algunas asociaciones, como la que ahora nos ocupa.

La versatilidad y diversidad de los espacios religiosos ibéricos a la que nos hemos referido en las primeras líneas de este trabajo no se aprecia únicamente cuando observamos el conjunto de la cultura ibérica, también ocurre en oppida particulares donde en ocasiones se identifican varios lugares sacros. Valga como ejemplo el oppidum de Edeta (Llíria, Valencia) donde se señala la existencia de un templo urbano en los departamentos 12, 13 y 14 de la manzana 4 y una habitación con posibles actividades rituales de carácter doméstico en el dep. 41 de la manzana 7, ambos con características y funciones distintas ${ }^{6}$. También se da esta variedad en el oppidum de La Serreta, donde se apuntan diversos puntos de referencia sacros. El primero de ellos es el célebre santuario localizado en los años 20 en la parte cimera de la montaña a partir de la acumulación de terracotas votivas $^{7}$. Este espacio se vincula claramente a la acrópolis de la ciudad y sin duda también al espacio comarcal, dada la búsqueda intencional del lugar de mayor prominencia visual desde el entorno con la finalidad de favorecer la agregación del paisaje político que presidía el oppidum. El segundo punto sacro se ubica en la fortificación de acceso a la ciudad. En el estrato de tierra que sirve de regularización del terreno y asiento de las estructuras de la torre y puerta de acceso oriental se encontraron algunos materiales que por su naturaleza sugieren una deposición inten-

testania Ibérica. Treinta años después. Alacant, pp. 73-90. Olcina, M. (2005): «El Tossal de Manises. La Illeta. La Serreta». En Abad Casal, L.; Sala Sellés, F.; Grau-Mira, I. (eds.) La Contestania Ibérica. Treinta años después. Alacant.

${ }^{6}$ Aranegui, C. (1997) cit. (n. 3); Bonet, H. (1995): El Tossal de Sant Miquel de Llíria: la antigua Edeta y su territorio. Valencia; Bonet, H. y Mata, C. (1997) cit. (n. 3).

${ }^{7}$ Visedo Moltó, C. (1922a): Excavaciones en el monte La Serreta, próximo a Alcoy, Memorias de la Junta Superior de Excavaciones Arqueológicas, 41, Madrid; Idem (1922b): Excavaciones en el monte La Serreta, próximo a Alcoy, Memorias de la Junta Superior de Excavaciones Arqueológicas, 45, Madrid.; Idem (1923): Excavaciones en el monte La Serreta, próximo a Alcoy, Memorias de la Junta Superior de Excavaciones Arqueológicas, 56, Madrid. 


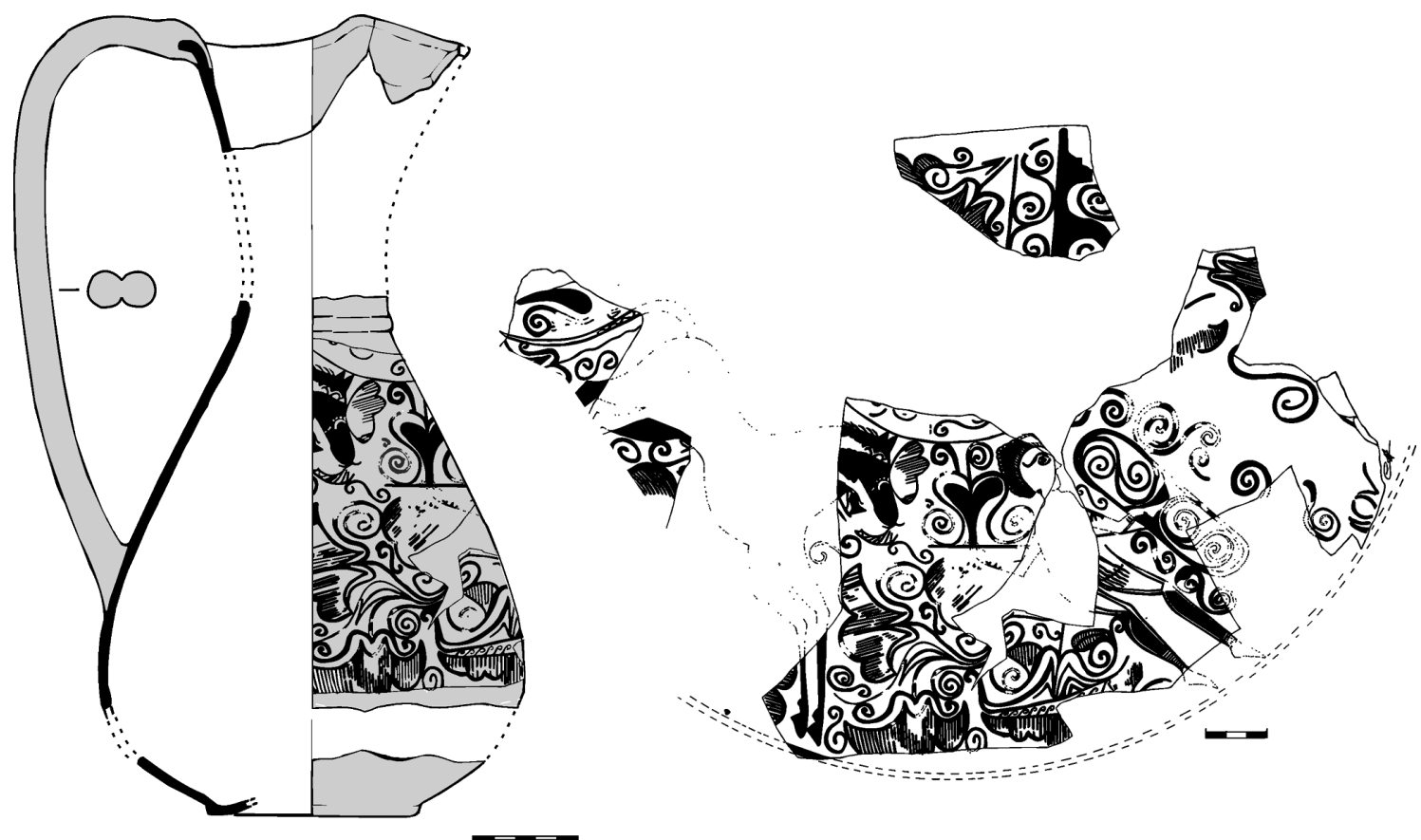

Fig. 2. Oinochoe de cerámica figurada procedente de la fortificación de acceso al poblado. Elaboración a partir de Llobregat et al. (1995) fig. 13.

cional de carácter votivo ${ }^{8}$. Se trata de vajilla de barniz negro, un oinochoe de cerámica figurada que muestra a un guerrero a pie, presto al ataque, al que sigue su caballo y representado entre vegetación floral (Fig. 2), tres terracotas pertenecientes a dos cabezas femeninas de distintos tipos y un grupo de varias figuras. Estos materiales en la base de la fortificación llevan a pensar en la práctica de un rito fundacional que sancionase la construcción de la obra defensiva.

El tercer punto donde situamos prácticas religiosas en el seno de la ciudad de La Serreta es el departamento $\mathrm{F} 1$ al que dedicaremos atención en este trabajo. En este caso se trata de una habitación de apariencia doméstica inserta en el entramado urbano de la ciudad del s. III a.C., pero con un repertorio material y algunas características de su construcción que diferencian claramente el espacio.

\section{ASPECTOS CONSTRUCTIVOS Y ESPACIA- LES DE LA HABITACIÓN SACRA DE LA SERRETA}

La singularidad de la habitación de estudio viene dada por el destacado ajuar que se recuperó en su in-

\footnotetext{
${ }^{8}$ Llobregat et al. (1995) cit. (n. 5): 152-154.
}

terior. Este conjunto se identificó durante el proceso de revisión de las excavaciones antiguas en la Serreta de los años 50 realizada por uno de nosotros ${ }^{9}$. Aquella investigación permitió contextualizar un conjunto que reunía algunas de las piezas destacadas del oppidum, especialmente en lo que corresponde a la concentración de un singular conjunto de imágenes en soportes diversos, como a continuación se detallará. Sin embargo, aunque el repertorio material es la característica más evidente de la excepcionalidad del espacio, el análisis detallado de las particularidades constructivas y su interrelación con la trama urbanística de la ciudad ofrece datos relevantes para la interpretación de la habitación y su importancia.

La habitación sacra es el departamento número 1 del sector $\mathrm{F}^{10}$ (Fig. 3) que constituye un barrio de un típico poblado en ladera cuya morfología urbanística se adapta a las empinadas laderas del cerro en que

\footnotetext{
${ }^{9}$ Grau Mira, I. (1996): «Los materiales de las excavaciones antiguas de 1953 y 1956 del poblado ibérico de La Serreta», Recerques del Museu d'Alcoi, 5, pp. 83-120

${ }^{10}$ Denominación asignada durante el levantamiento planimétrico y estudio urbanístico que se realizó de la Serreta a inicios de los años 90, cuando se designaron por orden alfabético los distintos barrios o zonas independizadas del yacimiento en Llobregat Conesa, E.A., Cortell Pérez, E., Juan Moltó, J. y Segura Martí, J.M. (1992): «El urbanismo ibérico en La Serreta», Recerques del Museu d'Alcoi, 1, pp. 37-70.
} 


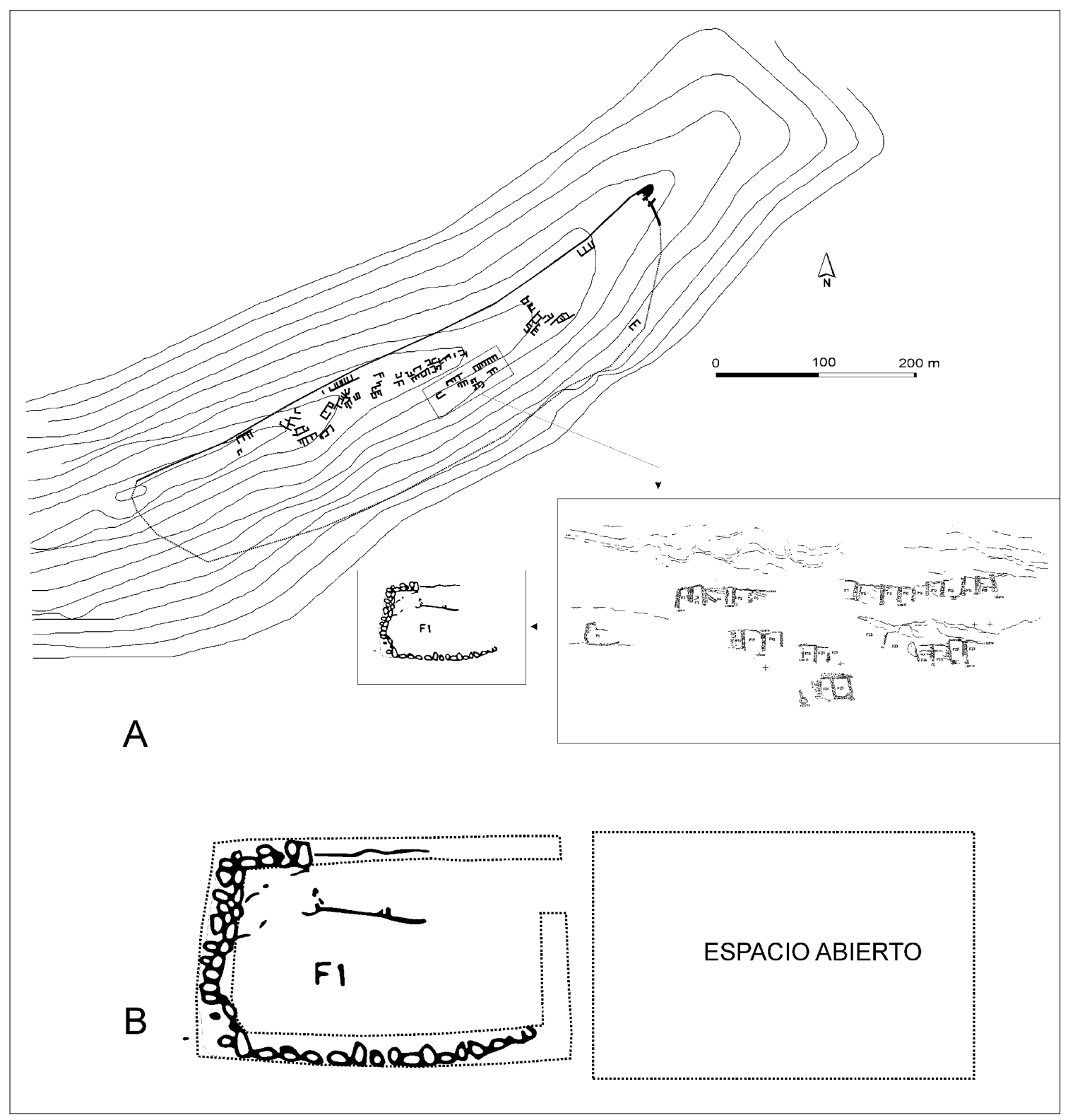

Fig. 3. Esquema del urbanismo de la Serreta y localización del sector F y departamento 1. Elaboración propia a partir de Llobregat et al., 1992.

se emplaza La Serreta. Este sector está formado por 29 departamentos que se extienden a lo largo tres terrazas paralelas situadas hacia el sureste del yacimiento y entre las cotas 1.009 y $1.000 \mathrm{~m} \mathrm{~s} / \mathrm{n} / \mathrm{m}$. Su disposición por las laderas se realiza en forma de alineaciones alargadas, con terrazas que siguen las curvas de nivel. Sobre estas plataformas se construyen los departamentos, que se adosan lateralmente. Este tipo de urbanismo geomórfico constituye un sistema flexible que se adapta a las condiciones topográficas del lugar. A la altura de la terraza central y separado por unos $15 \mathrm{~m}$ de las restantes estancias, se localiza el departamento 1, cuya ubicación y características constructivas lo apartan del patrón mostrado por los restantes departamentos.

Se trata de una estancia de aproximadamente $3 \mathrm{x}$ $5 \mathrm{~m}$, de mayor tamaño que los restantes habitáculos, cuyo lado mayor sigue el sentido de la curva de ni- 
vel. Le falta el muro oriental, donde presumiblemente se situaría el vano de acceso. La cámara se encuentra aislada del resto de departamentos, pues a diferencia de los restantes habitáculos del sector no aparecen construcciones adyacentes. Sin embargo, no podemos precisar a qué distancia empezarían a aparecer nuevas estancias debido a la falta de excavaciones en su entorno.

Los restos conservados de los muros son altos zócalos de piedra, realizados con mampuesto irregular trabado con barro y cuyo espesor es de aproximadamente $45-50 \mathrm{cms}$. La forma de las construcciones y la disposición junto a la plataforma sugiere la probable existencia de dos alturas en esta estancia: una planta baja que corresponde a las estructuras aún conservadas hoy día y cuyo acceso se realizaría desde la plataforma intermedia y un altillo sobre la cubierta de esta primera cámara al que se podría acceder desde la terraza superior. Este esquema organizativo se ha reconocido en las recientes excavaciones en el sector $\mathrm{I}^{11}$ y es posible suponerlo en otros departamentos de poblado con idéntica disposición y construcciones semejantes, aunque no podemos asegurarlo debido a las carencias del registro documental.

No consta la detección de ningún equipamiento o elemento constructivo doméstico que pueda observarse en la actualidad o llamase la atención de los excavadores en su momento. Únicamente se alude a un pavimento de tierra apisonada sobre el que se localizaron los hallazgos arqueológicos. Al respecto, debemos hacer mención de las escasas referencias disponibles de la excavación realizada por el lejano año de 1956. Esas mismas carencias de la documentación disponible afecta a la contextualización de algunos materiales. Por ejemplo, sabemos de la existencia de un gran lote de instrumentos de hierro con regatones, clavos, anillas, una azada, cadenas, rejas de arado, etc. aparecidos en el sector ${ }^{12}$, pero desconocemos cual de ellos pudo aparecer en la estancia $n .^{\circ} 1^{13}$.

El barrio o sector $\mathrm{F}$ fue erigido durante el s. III a.C., a juzgar por las evidencias arqueológicas recuperadas en su excavación, y por tanto, cabe atribuir esa misma cronología a la construcción de la habitación 1. Es precisamente con este barrio de la ladera con el que se vincula estrechamente el departamen-

\footnotetext{
${ }^{11}$ Olcina Domenech, M., Grau Mira, I. y Moltó Gisbert, S (2000), cit. (n. 5).

12 Pascual, V.(1956): «Nuevas excavaciones en La Serreta», periódico Ciudad de Alcoi, ejemplar del 4/XII/1956.

${ }^{13}$ La habitación n. ${ }^{\circ} 14$, integrante del templo urbano de Sant Miquel de Llíria también concentraba instrumentos de trabajo, Bonet, H. (1995) cit. (n. 6) y Bonet, H. y Mata, C. (1997) cit. (n. 3).
}

to de estudio y cabría relacionar su edificación con el proceso de ampliación de la ciudad y, en un sentido más amplio, con la constitución del nuevo marco ciudadano a fines de la época ibérica plena.

La ubicación del departamento aislado de las restantes construcciones de hábitat del sector F y ubicado al sudoeste de éstas, permite proponer que se reproduce la orientación y disposición espacial del santuario sobre la acrópolis con el oppidum, pero ahora a escala más reducida. En ambos casos encontramos la disposición de los edificios hacia levante, en una orientación hacia el orto solar de posible carácter astronómico. Hacia ese horizonte solar se dispone la agregación urbana en el caso del oppidum y el barrio en el caso del departamento de estudio. De ello podría desprenderse, con todas las cautelas, una axialidad que reforzaría el carácter sacro de esta habitación.

En segundo lugar, frente al departamento sacro se dispone un espacio de confluencia del tránsito, con un posible espacio abierto que vincula la trama urbana que se dispone en tres terrazas al este. Tal organización facilitaría una posible agregación de los habitantes frente al espacio singular, lo que pudo aprovecharse en las prácticas realizadas en la estancia en el supuesto de que la participación de un amplio colectivo requiriera un espacio adecuado. También la articulación del movimiento desde y hacia el poblado frente a este edificio lo convertiría en un nexo espacial que contribuiría a subrayar su relevancia.

En conclusión, frente a su apariencia de construcción común existen algunas particularidades que sin ser excesivamente elocuentes nos indican la singularidad del edificio. No parece que se escogiesen pautas de visibilidad material en la construcción del departamento, empleando materiales especiales y construyendo elementos destacados, pero sí que se aprecian algunos componentes que transmitirían la distinción del espacio.

En departamentos próximos de la misma barriada aparecen otras piezas destacadas, algunas excepcionales con iconografía heroica. Destacamos, sobre todo, una gran jarra (Fig. 4), completamente decorada, de la habitación denominada $\mathrm{F}^{14}$. Se trata de una jarra de asa bífida y cuyo cuello se separa de la panza con una moldura con sogueado pintado. La

${ }^{14}$ La descripción detallada e ilustración de esta pieza y otras que se detallan en este trabajo se encuentran en Grau Mira, I. (1996): cit. (n. 9). También en la reciente obra: Tortosa Rocamora, T. (2006): Los estilos y grupos pictóricos de la cerámica ibérica figurada de la Contestania, Anejos de Archivo Español de Arqueología, XXVIII, Madrid. 

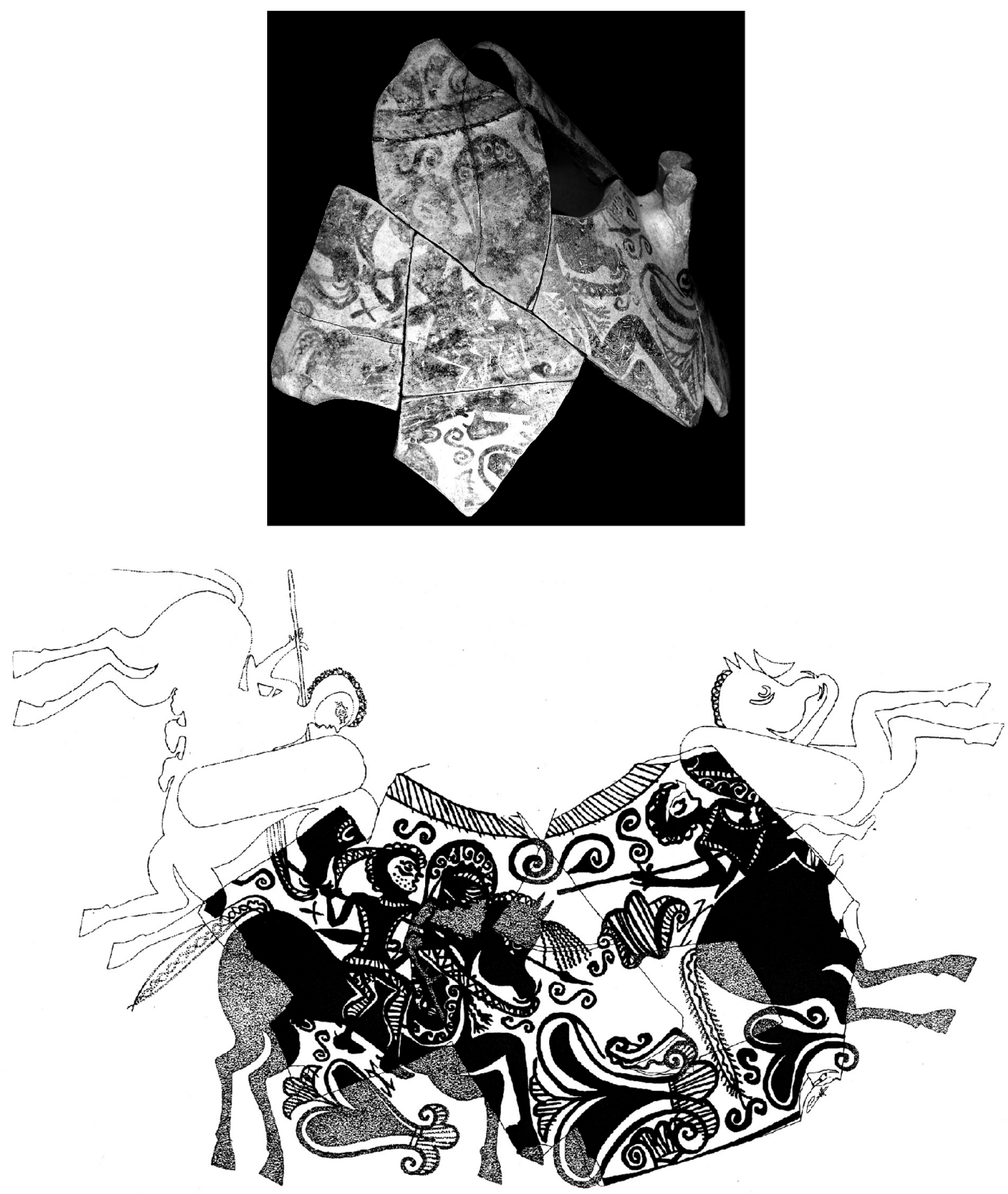

Fig. 4. Oinochoe de cerámica figurada procedente del departamento F9.

forma es próxima a la depositada en el fundamento del torreón de entrada y la iconografía repite el motivo del jinete. En este caso una procesión de tres varones a caballo, del que se conserva sobre todo el que se sitúa a la izquierda del asa, que es el que ini- cia el desfile y el que ha sido pintado en primer lugar. Es un varón barbado que enarbola lanza, falcata al cinto y gran escudo oval. Va calzado con espuelas. La tercera figura es imberbe y lleva al cinto puñal recto. Podría expresar una agrupación de varones 
ordenados jerárquicamente por edad ${ }^{15}$. Esta jarra es sin duda relevante, pero lo que la diferencia del caso que nos ocupa es el modo de aparición, pues en la habitación F1 destaca la concentración de un gran número de piezas, mientras que en la cámara F9 aparece aislada.

\section{EL REPERTORIO MATERIAL}

\subsection{LAS CERÁMICAS IMPORTACIÓN}

En el departamento F1 ha sido hallada una reducida pero significativa muestra de vajilla helenística de barniz negro principalmente campaniense $\mathrm{A}^{16}$. Estas piezas han aparecido en escaso número, apenas dos piezas de vajilla de mesa y una lucerna, parquedad de aparición que se compadece bien con las pautas distributivas observadas en el oppidum de La Serreta, donde hasta el momento no se conocen conjuntos numerosos hallados en un único espacio. La inexistencia de amplios lotes abundaría en la importancia y el valor de estas piezas que llegan mediante circuitos redistributivos de los bienes de prestigio procedentes del comercio mediterráneo.

Por lo que se refiere a las formas concretas aparecidas en el departamento, se trata de un cuenco de la forma Lamb $27^{17}$ (Fig. 5, 1), hasta el momento la más abundante entre las piezas del poblado de la Serreta, como se documenta en la fortificación de acceso $^{18}$, en el sector $\mathrm{B}^{19}$, en el Sector $\mathrm{I}^{20}$ y en otros departamentos del sector $\mathrm{F}^{21}$. La segunda forma atestiguada es el plato Lamb 36, atestiguado por un fragmento de pared y arranque de borde ${ }^{22}$. Estos platos también aparecen en otros repertorios del poblado, como en la fortificación de acceso anteriormente citada, pero su hallazgo es menos frecuente que los cuencos.

\footnotetext{
15 Este mismo orden jerárquico plasmado en la panoplia guerrera aparece en el Vas dels Guerrers, citado más adelante.

${ }^{16}$ Remitimos a Grau Mira, I. (1996) cit. (n. 9) donde se describen detalladamente, analizan y presentan ilustraciones del repertorio material, aquí únicamente resumiremos las características principales.

${ }^{17}$ Pasta marrón rojiza, fina y dura y con barniz denso, espeso y poco brillante. En el fondo exterior, marcas de digitaciones y manchas sin barnizar, propias del proceso de barnizado por inmersión de estos ejemplares.

${ }^{18}$ Llobregat Conesa, E. A. et al., (1995), pp. 135-162, cit. (n. 5).

19 Abad, L. (1983): «Un conjunto de materiales de La Serreta de Alcoy», Lucentum, II, pp. 173-197.

${ }^{20}$ Olcina Domenech, M., Grau Mira, I. y Moltó Gisbert, S. (2000): cit. (n. 5).

${ }^{21}$ Grau Mira, I. (1996), cit. (n. 9).

${ }^{22}$ La pasta es de color rosado oscuro y su barniz denso y brillante.
}

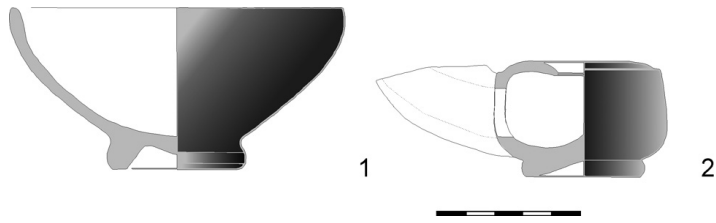

Fig. 5. Cerámica de barniz negro. 1: Cuenco Lamb. 27 de campaniense A; 2: lucerna Ricci D.

La tercera de las piezas de importación merece una atención especial, pues se trata de una lucerna helenística de cuerpo cilíndrico con pequeña moldura en el disco que corresponde a la forma Ricci D ${ }^{23}$ (Fig. 5,2 ). Estas lámparas son poco usuales en los poblados ibéricos y a diferencia de otras piezas de importación, nunca fueron imitadas por los ceramistas ibéricos. Por ello se ha propuesto que la iluminación estaría estrictamente regida por los ritmos diurnos o bien por el empleo de otros recipientes, como los pequeños cuencos de cerámica común empleados como lámparas ${ }^{24}$. No hay otros recipientes que hubiesen podido emplearse para iluminar en la estancia que nos ocupa. Y cabe destacar que piezas idénticas del entorno cercano las encontramos en contextos religiosos, como los que se consideran lugares de culto edetanos: el templo de Sant Miquel de Llíria y el departamento 1 de El Puntal dels Llops $^{25}$. Esta circunstancia nos indica la importancia de la iluminación artificial o el simbolismo asociado a la lucerna como portadora de luz en estos contextos litúrgicos.

El estudio de la vajilla helenística importada nos faculta para situar con claridad el momento de abandono del espacio, dada la precisión con la que hoy se conocen estas piezas en los contextos ibéricos. En efecto, las piezas estudiadas se corresponden con un repertorio correspondiente a la producción de campaniense A que es habitual en poblados ibéricos del último momento de la época clásica ibérica, a fines el s. III o inicios del s. II a.C. Corresponden a un repertorio formado principalmente por las formas Lamb 23, 27, 36, Morel 68 correspondientes al grupo de campaniense A media, definido por Morel y datado entre el 200-180, generalmente asociados al avance de las tropas romanas a inicios del

${ }^{23}$ El pico, alargado y estrecho, con un pequeño apéndice lateral a la derecha, sin perforar. La pasta es rosácea y el barniz liso y de color rojizo.

${ }^{24}$ Teoría propuesta por Luzón, J. M. (1973), Excavaciones en Itálica, Estratigrafía en El Pajar del Artillo (Campaña, 1970). E.A.E, 78, Madrid, p. 37.

${ }^{25}$ Bonet, H., Mata, C. y Guérin, P. (1990): «Cabezas votivas y lugares de culto edetanos», Verdolay, 2, pp. 191-192. 
s. II a.C. ${ }^{26}$. Frente a esta datación clásica, en la investigación actual existe una tendencia a la revisión de este aserto, proponiendo que la llegada de esta facies cerámica podría corresponder a los momentos de la Segunda Guerra Púnica a fines del s. III a.C., puesto que estos tipos ya están presentes en la Cartagena Bárquida ${ }^{27}$.

Además del indicador cronológico preciso, las vajillas plantean la cuestión de la vinculación de la presencia bárquida en el área en los momentos de la Segunda Guerra Púnica. En otras ocasiones se ha señalado la clara vinculación comercial de La Serreta con El Tossal de Manises en la costa de Alicante ${ }^{28}$ de donde procederían los productos del Mediterráneo que se encontrarían en la ciudad del interior. La intensa impronta púnica en el fortín alicantino ha llevado a su excavador ${ }^{29}$ a proponer que la construcción de El Tossal se debe a la política bárquida de fortalecer su presencia en el litoral oriental de la Península. Ello supondría una proximidad geográfica y una presencia comercial, cuanto menos, que no debe obviarse para comprender qué sucedía en La Serreta. Por lo que respecta a nuestro estudio, no debe perderse de vista el elemento púnico como vector transmisor al mundo ibérico de prácticas y creencias religiosas de raigambre mediterránea, especialmente intensa en la zona sudoriental de la península.

\subsection{LAS CERÁMICAS IBÉRICAS}

Las cerámicas ibéricas constituyen el lote de materiales más numeroso recuperado en el espacio sacro. Se trata de un conjunto muy uniforme formado por cuarenta y dos piezas pertenecientes a 5 tipos formales distintos y funcionalmente destinados únicamente a servir de recipientes de almacenaje y despensa (Fig. 6). Es decir, un elenco muy limitado de tipos dentro de la amplia tipología que ofrece la vajilla ibérica reconocida en el asentamiento de $\mathrm{La}$

\footnotetext{
${ }^{26}$ Morel, J.-P. (1980): «La céramique campanienne: acquis et problèmes», en Lévêque P. y Morel, J.-P. (eds.): Céramiques hellénistiques et romaines. Annales Littéraires de l'Université de Besançon, 242, pp. 85-122.

${ }^{27}$ Principal-Ponce, J. (1998): Las importaciones de vajilla fina de barniz negro en la Cataluña litoral y occidental en el s. III a.C., Comercio y dinámica de adquisición en las sociedades indígenas, Oxford; Idem (2004): «La vajilla de barniz negro itálica de época ibérica en Cataluña. Tradiciones productivas y prácticas sociales», en Olmos, R. y Rouillard, P. (eds.), La vajilla ibérica en época helenística (siglos IV-III al cambio de era), Madrid; Sala, F. (1998): «Los problemas de caracterización del s. III a.C. en los yacimientos de la Contestania»: Arqueo-Mediterránea, 4, pp. 29-48.

${ }^{28}$ Olcina, M. et al. (1998) cit. (n. 5).

${ }^{29}$ Olcina, M. (2005) cit. (n. 5).
}

Serreta y que, como veremos, nos servirá para aproximarnos a las prácticas realizadas en el lugar. Un segundo aspecto que conviene destacar de inicio se refiere a la decoración de estos recipientes, pues existe un reducido número de vasos que acogen decoraciones de tipo excepcional con la aparición de motivos de carácter figurativo humano y vegetal que conforman complejas escenas y ricas composiciones. Dedicaremos un epígrafe especial a estos vasos de especial riqueza decorativa, veamos primeramente una breve descripción formal y funcional del conjunto de $\operatorname{vasos}^{30}$.

La cerámica ibérica corresponde exclusivamente al tipo fino de pasta clara, sin que aparezcan las cerámicas de cocina realizadas con pastas groseras de desgrasantes vistosos y de cocción reductora. En esta cerámica fina predomina la decorada con motivos pintados de tipo geométrico, bien a base de líneas o filetes o composiciones más complejas en que interviene el pincel múltiple y el compás para crear motivos como círculos concéntricos, los denominados tejadillos, etc...

Corresponden a esta cerámica decorada las piezas de despensa o almacenaje doméstico con formas como urnas de bordes moldurados, con nueve ejemplares de tamaño mediano, o los kálathoi, representados por tres ejemplares, uno de pequeño tamaño y motivos geométricos y otros dos de mayor porte con decoraciones complejas. Encontramos también ocho lebetas de diversos tamaños; predominan los grandes recipientes abiertos con decoración de líneas y filetes, pero aparecen piezas menores con bordes planos y moldurados. Completan este conjunto ocho grandes tinajas contabilizadas a partir de elementos formales como sus bordes o por ejemplares casi completos, como el denominado Vas dels Guerrers y otras piezas con decoración vegetal.

La cerámica común sin decorar está representada en nuestro espacio de estudio por las típicas ánforas de cuerpo de odre, hombro redondeado y ligero borde saliente con labio almendrado con un total de trece ejemplares. Ánforas a las que hay que añadir otros tres ejemplares que presentan bordes distintos, bien de labio plano en dos casos o uno de perfil cuadrangular y cuello cilíndrico que imita las producciones de ánforas ibicencas del tipo ramón T. 8.1.3.1. realizada en pasta ibérica local.

La primera observación que debemos realizar ante este elenco es que nos encontramos claramente ante

\footnotetext{
${ }^{30}$ Por mor de la brevedad, nuestra descripción será necesariamente esquemática. En Grau Mira, I. (1996) cit. (n. 5) el lector encontrará un estudio detallado y paralelos tipológicos de las piezas cerámicas aquí sucintamente descritas.
} 

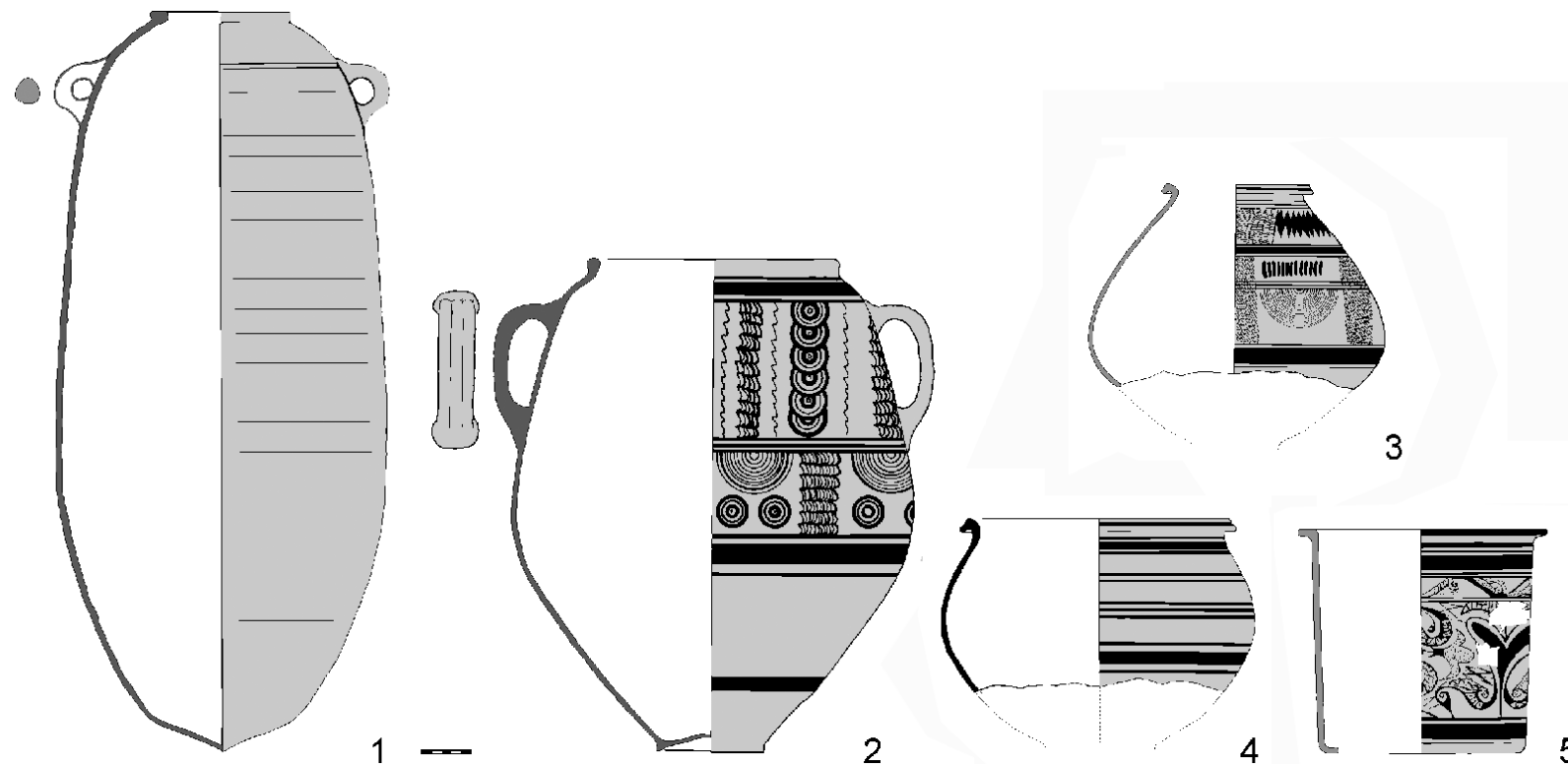

Fig. 6. Tipos de recipientes de cerámica ibérica presentes en el departamento F1: 1: ánfora; 2: tinaja; 3: tinajilla; 4: Lebes; 5: Kálathos.

un contexto que se aparta del que podríamos considerar propio de un ámbito doméstico del poblado de La Serreta, perfectamente reconocido gracias a las citadas excavaciones en el sector I y la revisión de otros repertorios. En primer lugar, cabe mencionar la absoluta ausencia de cerámicas de cocina y vajillas de mesa que permitan suponer la presencia de un grupo doméstico preparando y consumiendo sus alimentos habituales. A lo sumo podría pensarse en el uso de la vajilla de barniz negro, un cuenco y un plato, para cubrir el servicio de mesa, pero son escasas dos piezas para tal fin y no explicarían la carencia de cerámicas para cocinar los alimentos. En segundo lugar, predominan los recipientes de despensa y almacenaje cuya capacidad de conservación de productos, en caso de encontrarse en uso al mismo tiempo, excedería ampliamente las necesidades de una unidad doméstica. Antes bien, la concentración de 16 ánforas, quizá en un altillo ${ }^{31}$, casi triplican las seis recuperadas en la unidad doméstica identificada en el sector $\mathrm{I}^{32}$, aunque se aleja de otras concentraciones notables, verdaderos almacenes identificados en el mundo ibérico. A las ánforas hay que sumar la capacidad de conservación de productos de las

\footnotetext{
${ }^{31}$ Carecemos de datos concretos para la ubicación de las ánforas en un altillo del departamento $F 1$, pero apuntamos esta posibilidad por comparación en el modo de aparición en el departamento del sector I.

${ }^{32}$ Olcina Domenech, M., Grau Mira, I. y Moltó Gisbert, S. (2000) cit. (n. 5).
}

restantes piezas que, en un tamaño u otro, todas parecen responder la función de despensa, desde los kálathoi que pudieron conservar frutos carnosos conservados en miel hasta los grandes recipientes para almacenamiento de áridos, cerveza, vino o incluso agua, como parecen sugerir los análisis realizados en ejemplares de otros yacimientos ibéricos ${ }^{33}$. Deberemos retener este rasgo funcional del conjunto cerámico a la hora de aproximarnos a la función del espacio sacro.

\subsection{LAS CERÁMICAS IBÉRICAS CON DECORACIÓN EXCEPCIONAL}

Sin apartarse de la función de almacenamiento atribuida, como hemos dicho, algunos vasos acogen una decoración pintada de carácter excepcional de carácter figurado. En concreto nos referimos al pithos con decoración figurada conocido como el Vas dels Guerrers, el kálathos de la paloma, el kálathos de la eclosión vegetal y otros dos pithoi con motivos vegetales en una banda central.

\footnotetext{
${ }^{33}$ Inferimos la propuesta de contenidos de los trabajos Juan Treserras, J. (2000): «Estudio de contenidos en cerámicas ibéricas del Torrelló de Almazora», en Clausell, G., Izquierdo, I. y Arasa, F.: «La fase del Ibérico Final en el asentamiento del Torrelló del Boverot (Almazora, Castellón)», Archivo Español de Arqueología, 181-182, pp. 103-104 y Juan Treserras, J. y Matamala, J. C. (2004): «Los contenidos de las ánforas en el Mediterráneo Occidental. Primeros resultados», Arqueomediterránea, 8, pp. 283-291, entre otros.
} 


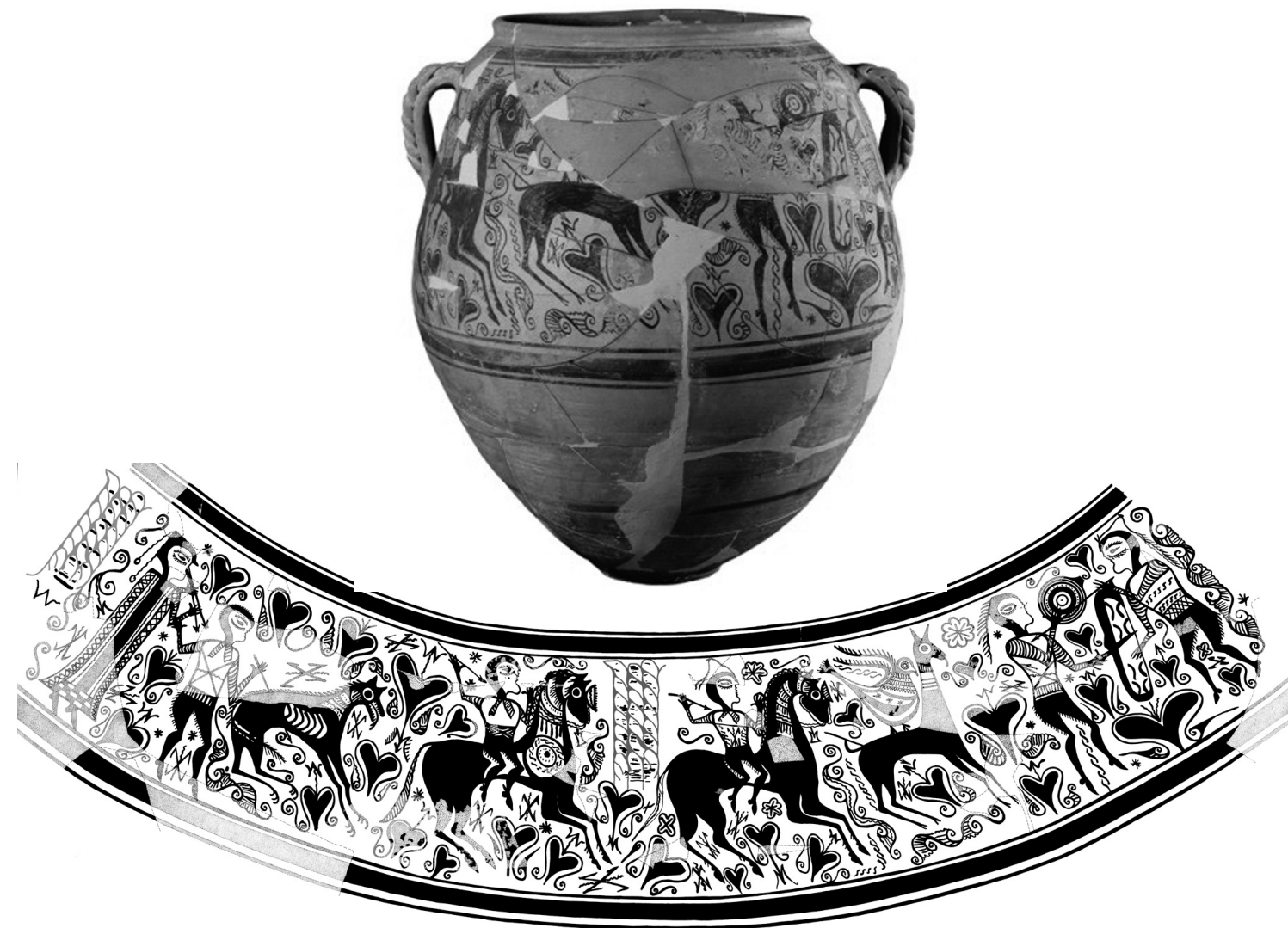

Fig. 7 y 8. El Vas dels Guerreres. Calco de la decoración de El Vas dels Guerreres. El punteado representa una propuesta hipotética de restitución de las figuras perdidas (Dibujo E. Cortell, Museu d'Alcoi).

Vas dels Guerrers. Se trata de una gran tinaja de forma ligeramente ovalada de $66 \mathrm{~cm}$ de altura y $59 \mathrm{~cm}$ de diámetro máximo, con el borde engrosado y grandes asas trenzadas (Fig. 7). Se trata de la principal muestra de decoración figurada de estilo narrativo, también llamado Oliva-Lliria, de La Serreta ${ }^{34}$. Muestra la representación de jinetes e infantes armados en escenas de iniciación, caza y combate, acompañados de una profusa decoración vegetal. A través de la narración en un gran friso continuo se recrea una secuencia de tres hazañas (Fig. 8): la primera de ellas muestra un joven que se enfrenta a una fiera; la segunda representa a dos jóvenes jinetes que cabalgan a la caza de un ciervo; la tercera escena plasma un combate singular de infantes. Todo ello envuelto en el tiempo mítico que sitúa la música que hace sonar una joven con su diaulós en el inicio de las

\footnotetext{
${ }^{34}$ Remitimos al estudio reciente Olmos, R. y Grau Mira, I (2005): «El Vas dels Guerrers de la Serreta», Recerques del Museu d'Alcoi, 14, pp. 79-98, donde se ofrece un detallado análisis de la pieza; véase también Tortosa Rocamora (2006) cit. (n. 14).
}

escenas. Estos episodios relatan en progreso e intensidad gradual la historia o biografía de un héroe, a través de un proceso iniciatico.

Kálathos de la eclosión vegetal. Se trata de un vaso de forma cilíndrica con el borde plano vuelto al exterior (Fig. 9). Se conserva incompleto, pues le falta su base. La pasta cerámica es de color anaranjado claro en su superficie y ligeramente más oscura en su sección. La decoración está pintada en tonos rojizos y cuenta con motivos de dientes de lobo en el borde del vaso y principalmente un gran friso central enmarcado por bandas y filetes; en esta banda se dispone la decoración vegetal compleja y profusa, en la que abundan los brotes y zarcillos, las esquematizaciones en forma de estrella y una franja vertical con ajedrezado jalonada de espirales. Estos elementos se disponen en torno a una gran hoja de hiedra de forma lanceolada de la que parten la mayor parte de los brotes vegetales. En la parte opuesta del vaso se pinta una hoja tripétala representada en sección que preside el panel decorado. 


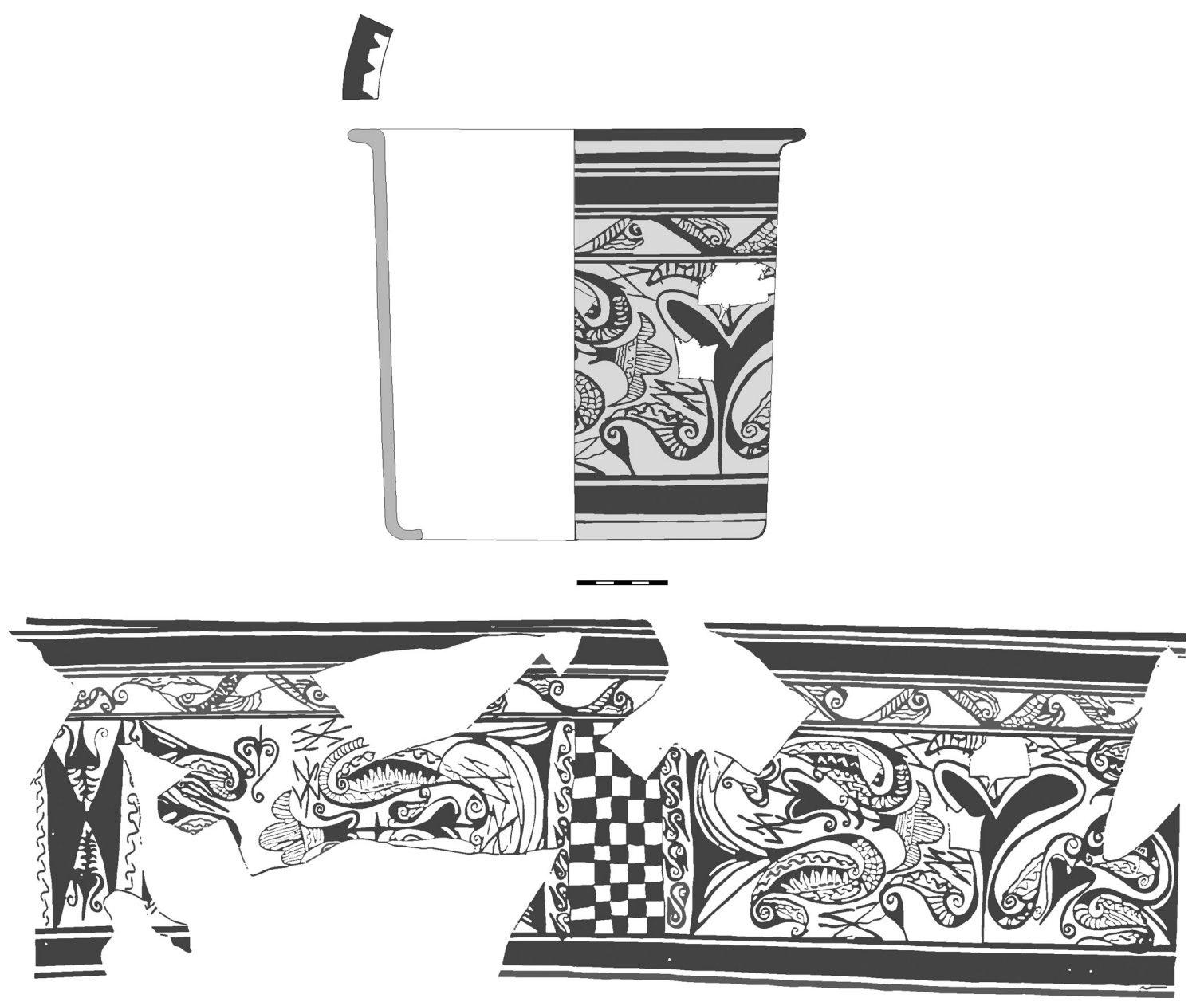

Fig. 9. Kálathos de la eclosión vegetal.

Kálathos de la paloma. Es un recipiente de cuerpo de tendencia cilíndrica, aunque ligeramente troncocónico (Fig. 10). Posee el borde moldurado, la base cóncava y como elemento de sujeción sendas asas horizontales trenzadas, de la que se conserva una. La pasta cerámica es anaranjada clara y con una capa de barbotina rosada en su superficie; características que comparte con el Vas dels Guerrers y nos llevan a presumir que tal identidad técnica se debe a que proceden del mismo artesano y posiblemente de un mismo lote de realización, conjetura que se avala con la similitud de algunos motivos decorativos y del asa trenzada descrita con función únicamente decorativa y que singulariza simbólicamente el vaso. La decoración está pintada en tonos vinosos y se compone de un gran friso delineado entre bandas y filetes en el que aparece como motivo central una gran paloma picoteando un bulbo, posiblemente una cápsula de adormidera en eclosión $^{35}$. En la parte posterior del friso aparece una gran hoja de hiedra lanceolada que se acompaña de lianas y tallos. Bajo el amparo que forma la visera del asa horizontal se pinta una esquematización de brote vegetal, comúnmente llamado zapatero, de gran tamaño. En la zona inferior, independientemente del friso central decorado, aparece una banda de semicírculos concéntricos entrelazados.

Pithos vegetal I. Gran vaso bitroncocónico con borde almendrado y hombro ligeramente marcado que se conserva incompleto, pues le falta el tercio infe-

${ }^{35}$ Este mismo motivo de la cápsula de adormidera aparece en otra tinajilla de La Serreta, la núm. 2335. este motivo vegetal ha sido recientemente objeto de un detallado estudio. Véase Mata, C., Badal, E., Bonet, H., Collado, E., Fabado, F.J., Fuentes, M., Izquierdo, I., Moreno, A., Ntinou, M., Quixal, D., Ripollés, P.P., Sorial, L. (2007): «De lo real a lo imaginario. Aproximación a la flora ibérica durante la edad del Hierro», Anales de Arqueología Cordobesa, 18, pp. 93-122. 

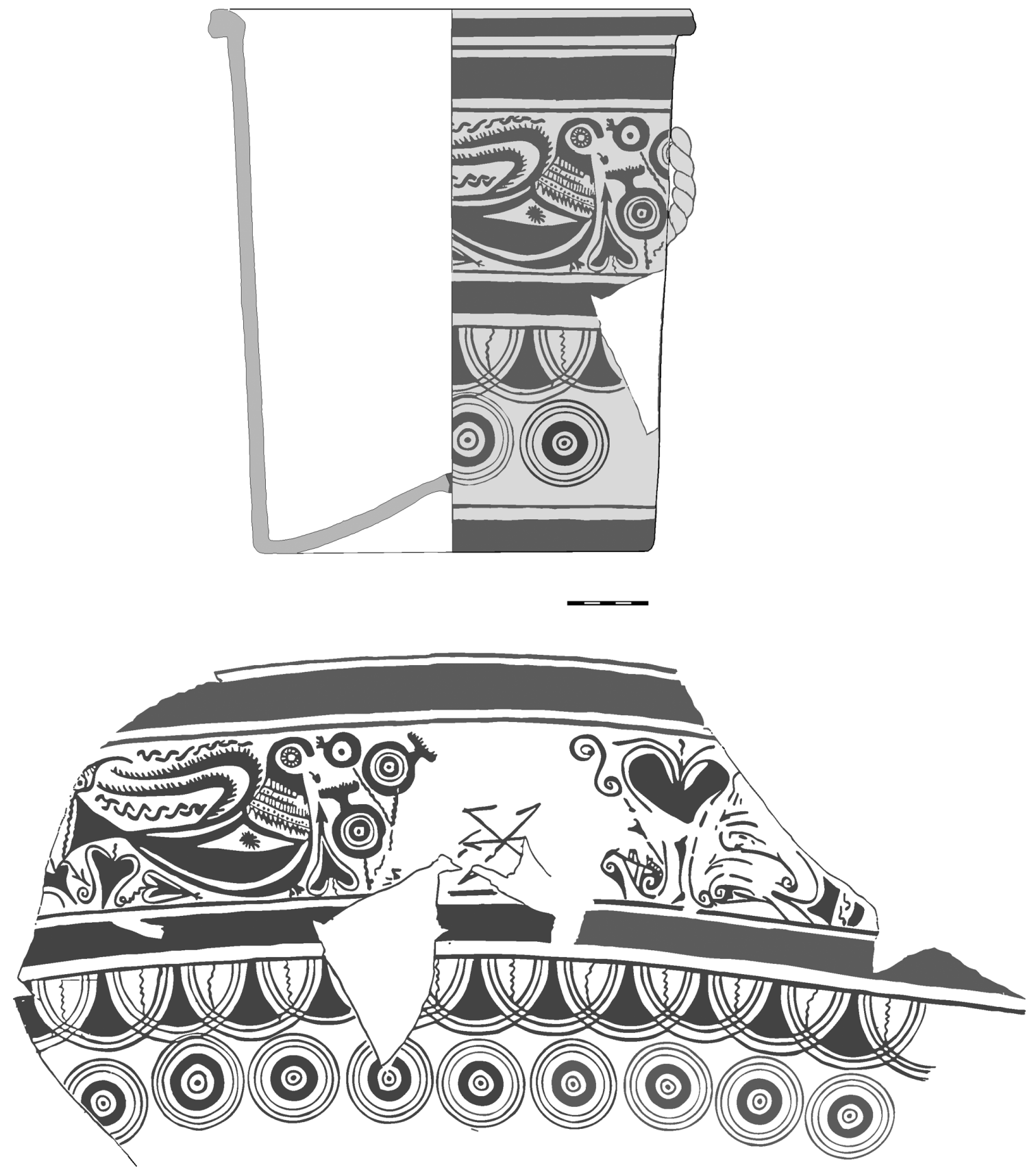

Fig. 10. Kálathos de la paloma.

rior y parte de la zona superior (Fig. 11). Posee el borde engrosado. La pasta cerámica es de color anaranjado y la decoración pintada en tono vinoso a base de bandas y filetes que separan dos frisos: en el superior aparecen motivos vegetales que no se pueden identificar con claridad al faltar parte de las paredes del vaso, pero se intuyen grandes hojas de hiedra, zarcillos, etc. El friso inferior está compuesto por un conjunto de pequeños círculos concéntricos unidos de forma horizontal y alternando con líneas en zigzag, por debajo aparecen tejadillos verticales que compartimentan el espacio en metopas en las que aparecen semicírculos concéntricos, arriba, y líneas en zigzag, debajo. 


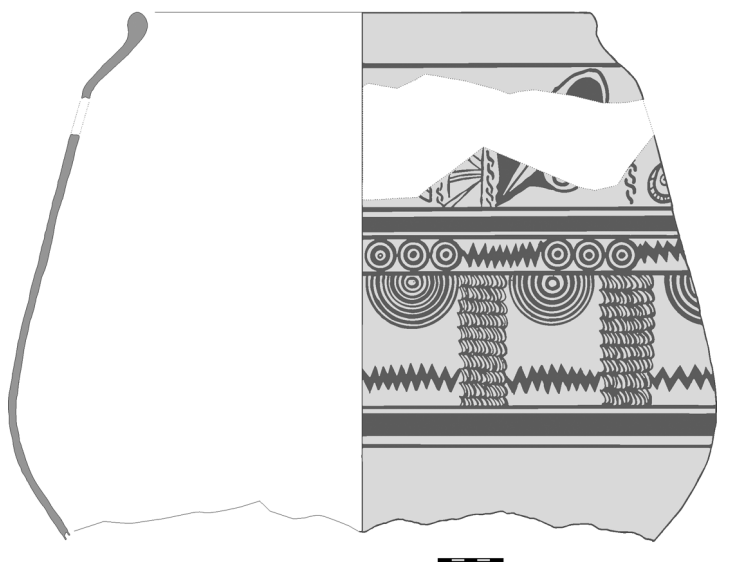

Fig. 11. Pithos vegetal I.

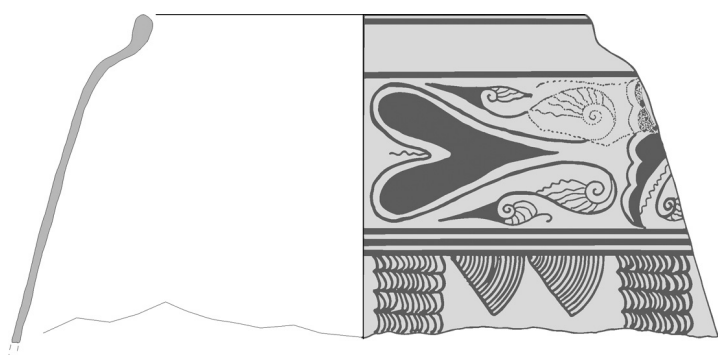

Fig. 12. Pithos vegetal II.

Pithos vegetal II. Gran vaso bitroncocónico con borde almendrado y hombro ligeramente marcado que se conserva incompleto, pues únicamente se recuperó el tercio superior (Fig. 12). La pasta cerámica es de color anaranjado claro y la decoración de color vinoso a base de filetes que separan dos frisos, el superior con motivos fitomorfos, con restos de dos grandes hojas de hiedra con forma lanceolada y zarcillos que las contornean. El friso inferior está ocupado por tejadillos en sentido vertical y segmentos de círculos concéntricos.

\subsection{LA Plaqueta de terracota}

\section{Descripción}

Una de las piezas más emblemáticas de la Serreta es la conocida terracota comúnmente conocida como el grupo de la Diosa Madre (Fig. 13). Aunque tradicionalmente se asocia al santuario, se encontró en la habitación que nos ocupa. Se trata de una plaqueta de arcilla rojiza modelada a mano de $18,2 \mathrm{~cm}$ de anchura y 16 '7 de altura que muestra un grupo de

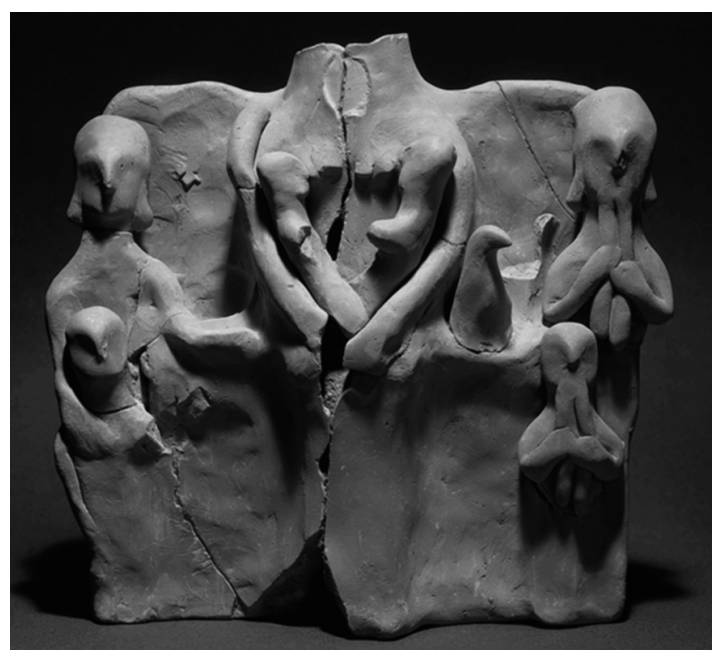

Fig. 13. Plaqueta de terracota con divinidad nutricia.

personajes en tamaños y actitudes diversas y que están realizados a partir de un modelado manual de la arcilla de forma esquemática. Preside la escena una gran figura femenina central incompleta, pues carece de la cabeza, y que acoge en su seno a dos niños pequeños a los que amamanta. Dentro del esquematismo de la representación es posible apreciar un gran manto o velo que cae de la cabeza y que acogería a las figuras lactantes, aunque es difícil distinguir los brazos del pliegue del vestido. Sin embargo, numerosos paralelos apoyan esta función del mostrarse y simultáneamente acoger, que es protección bajo el manto divino. Por ejemplo, el mismo motivo y esquema de representación, la acogida bajo el manto

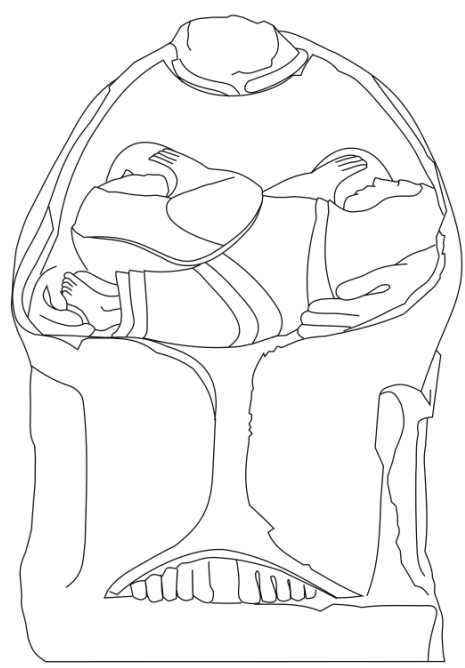

Fig. 14. Divinidad nutricia de Megara Hyblea (dibujo de S. Olmos). 


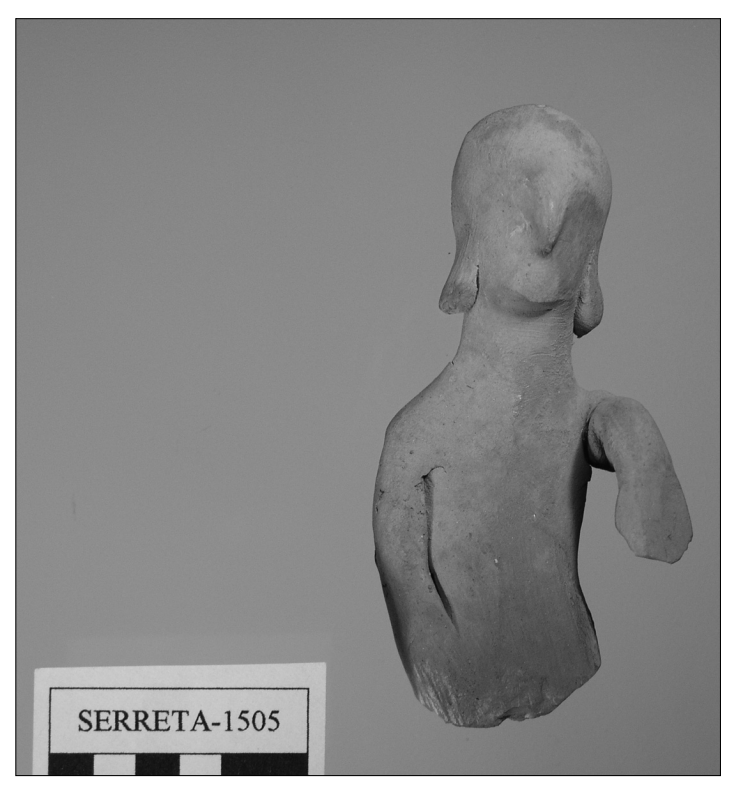

Fig. 15. Figura de terracota perteneciente a un grupo.

a dos lactantes aparece en la escultura de la diosa nutricia de Megara Hyblaea (Fig. 14) ${ }^{36}$.

Está sentada en un trono que constituye la parte trasera de la pieza. Esta figura central se acompaña de sendas parejas de mujeres e infantes de proporciones menores a las de la señora sentada, en sus laterales. Los rostros se realizan con un simple pellizco de arcilla en el que individualizan algunos rasgos, como los bucles del cabello que penden de ambos lados de la cabeza. La figura de la derecha acoge a la figura infantil con el brazo derecho posado sobre el hombro -un gesto familiar- mientras que con el izquierdo toca el regazo de la figura central o el mismo trono, como también aproxima su brazo a la figura sedente la figura infantil. Por su parte, las figuras de la izquierda tocan el diaulós que dan sentido singular a una escena envuelta en el entorno de la música ${ }^{37}$. Entre estas figuras y el personaje central aparece una paloma. Una segunda paloma se situaría probablemente en el espacio simétrico del trono, a la izquierda.

La pieza tiene una base plana y un reverso liso con un agujero central debido a las necesidades técnicas de fabricación. Presenta, por tanto, una única

\footnotetext{
${ }^{36}$ Nos referimos a la conocida estatua kurotropha de Megara Hyblaea custodiada en el Museo Paolo Orsi de Siracusa, Sicilia.

${ }^{37}$ Sobre la relación de la música, en concreto la aulética, con el ámbito de la diosa, con frecuencia se ha indicado la omnipresencia de este instrumento y en, especial, acompaña la aproximación procesional a la Diosa. Véase el Thesaurus of Cultus et Rituum Antiquorum, vol. II. (2004). The Paul Getty Museum, Los Angeles, pp. 347 y sig.
}

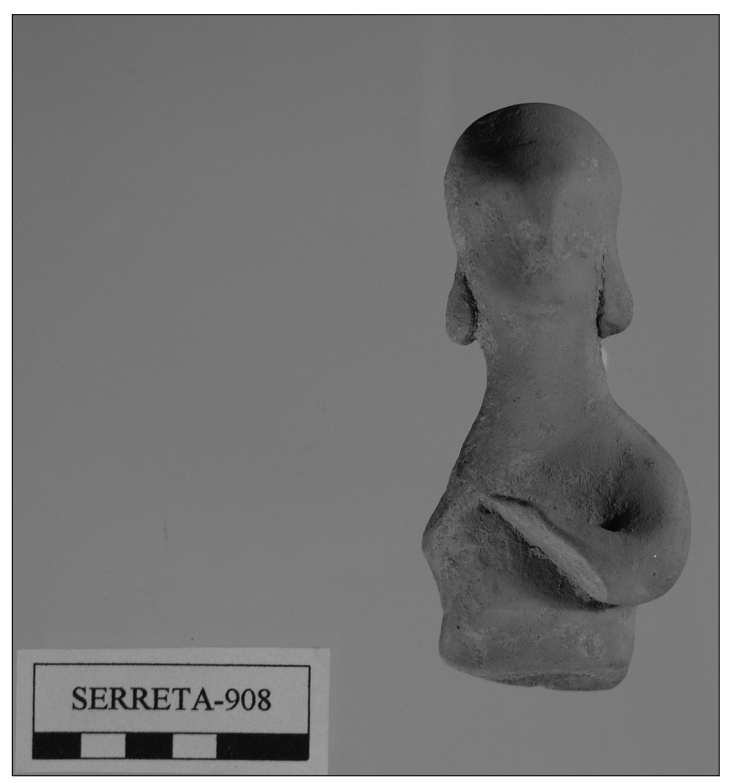

Fig. 16. Figura de terracota perteneciente a un grupo.

cara decorada, para ser mostrada de frente ${ }^{38}$ sobre una pequeña peana o bien en una hornacina.

\section{Paralelos}

Este grupo no es único en el yacimiento de La Serreta. De procedencia indeterminada, pero probablemente de la zona de la acrópolis dónde se ubica el santuario, proceden al menos dos figuras muy semejantes a la de la habitación F1. Un fragmento muestra una mujer con el brazo derecho junto al cuerpo y el izquierdo adelantado para acoger probablemente a una figura de menor tamaño (Fig. 15). Tendríamos muy probablemente a una madre, o una adulta, con un niño. Esta figurilla es del mismo taller que el de la plaqueta y responde a un grupo similar, si bien la disposición de uno de los brazos es inversa. Lo que es seguro en este segundo caso es que el brazo que se adelanta acogería una segunda figura. No podemos precisar si ambas figuras se asocian a un grupo mayor. Una segunda terracota con similar peinado femenino dobla el brazo izquierdo por el codo tal vez en el gesto de entrar en contacto con un objeto o personaje a su derecha (Fig. 16). Posiblemente pertenecen a un grupo que ofrece variaciones

\footnotetext{
${ }^{38}$ Parte de la descripción y las ideas vertida sobre la pieza han sido presentadas anteriormente por uno de nosotros: Olmos, R. (2000-2001): «Diosas y animales que amamantan: la transmisión de la vida en la iconografía ibérica», Zephyrus, 53-54, pp. 353-378.
} 


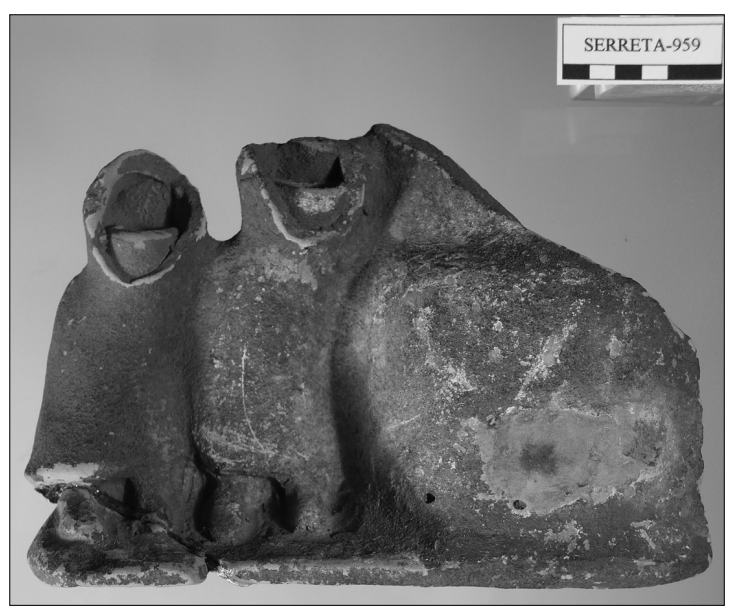

Fig. 17. Fragmento de grupo de terracota con figura central sedente y fieles a un lado.

claras con nuestra placa, pero que a su vez muestran una unidad de taller. Otros elementos relacionados con este grupo es el fragmento de busto femenino muy desgastado y de mayor tamaño a los descritos hallado en los niveles fundacionales de la fortificación de acceso al oppidum ${ }^{39}$ y cuyo gran tamaño ya fue relacionado en la publicación original como posible referencia de la figura central de la plaqueta de la diosa nutricia.

Otros fragmentos procedentes de la acrópolis muestran grupos de varias figuras dispuestas frontal-

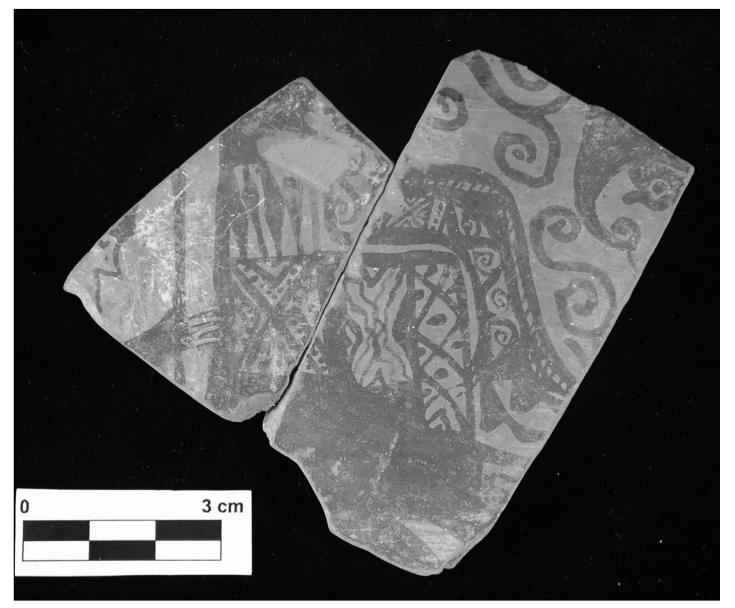

Fig. 18. Fragmento de cerámica con decoración figurada que representa un hombre que llega desde la izquierda y toca con su mano el respaldo del trono de la divinidad. Para enfatizar el contacto se han hecho ligeras incisiones sobre la mano pintada.

${ }^{39}$ Llobregat Conesa, E.A. et al. (1995) cit. (n. 5) nota 10, lám. 8 . mente, presentándose, que recuerdan la placa. Entre ellos destaca la parte inferior de una terracota incompleta que muestra tres figuras. Conforman probablemente un grupo originario en el que la figura central sería sedente de mucha mayor anchura y a su derecha dos personajes de pie cuyo cuerpo se inclina hacia el personaje central. El esquema que proponemos es el de dos devotos junto a la efigie de la diosa (Fig. 17). En este caso parece que se reproduce el motivo por un taller distinto. Otras terracotas muy fragmentarias corroborarían la existencia repetida de imágenes votivas en que lo importante es la representación de grupos, tal vez familiares, generalmente en su mostración frontal.

El motivo del fiel que se aproxima a la imagen divina lo describe un fragmento cerámico de La Serreta (Fig. 18). El hombre en este caso llega desde la izquierda y toca con su mano el respaldo del trono de la divinidad. Delante del trono la gran silueta negra puede ser la prótome de un animal, como un lobo, que enmarca y protege el trono, se intuyen rasgos del ojo y las fauces abiertas. Pero sobre todo nos interesa el gesto del fiel. Los dedos excepcionalmente se marcan con incisiones sobre la superficie cerámica para subrayar el gesto sagrado del contacto. Es el mismo gesto de la mujer y el niño de la izquierda en la placa de terracota.

En definitiva, nos encontramos con la presentación ante la diosa que se transforma en un motivo ante el espectador. Disuelve la espacialidad en frontalidad, recurso plástico propiamente ibérico.

\subsection{LA HERRAMIENTA DE ORFEBRE}

Los hallazgos arqueológicos de herramientas que podemos asignar con exclusividad al trabajo del oro o de la plata son extraordinarios por diversas razones. En primer lugar porque las herramientas del orfebre son objetos que pueden llegar a ser muy especializados, incluso personalizados, fabricados por el propio artesano adaptándose a su forma de hacer y trabajar; formas y medios que se transmiten durante generaciones, se transforman y reciclan, de manera que el resultado es una ausencia del documento arqueológico. En el lado contrario tenemos las herramientas versátiles que pueden ser utilizadas para cualquier trabajo metalúrgico sin distinción; entre ellas estarían toda una serie de objetos de bronce, como punzones, cinceles, varillas, martillos y moldes que pudieron emplearse durante alguna fase del proceso de transformación de cualquier metal. Una tercera categoría de herramientas serían aquellas fa- 
bricadas en materiales perecederos que tampoco han sobrevivido al paso del tiempo; la cuerna y las maderas duras son materiales perfectamente válidos para determinadas tareas de orfebrería y actualmente todavía se utilizan mazas de madera para la fase final de procesos de deformación plástica; pero también algunos materiales marinos como conchas o jibias, y otros vegetales y animales, como textiles y sustancias ácidas o aglutinantes.

Existe, no obstante, otra fuente de información que nos permite conocer el tipo de herramientas que se utilizaban en los distintos procesos técnicos del trabajo orfebre, que son las huellas y microhuellas de trabajado. Cada herramienta deja sobre la superficie del metal, o en su estructura interna, una huella característica que es prueba de su existencia y utilización; lo mismo que la propia herramienta se desgasta y deforma según las peculiaridades de su propio uso. Otra cosa es que seamos capaces de ver e interpretar estas huellas correctamente. En general, la lupa binocular de altos aumentos es la herramienta más versátil y útil para el investigador. Por otro lado, la analítica no destructiva para el conocimiento de la composición química del metal o la aleación que estemos estudiando, por cualquiera de los métodos que actualmente están al alcance del arqueólogo, es un paso previo ineludible para no errar en nuestras interpretaciones. Estos fundamentos metodológicos se han utilizado en el estudio de la extraordinaria herramienta encontrada en el departamento F1 de La Serreta de Alcoy.

\section{Una herramienta multiuso}

El hallazgo de esta herramienta es extraordinario porque se trata de la primera vez que se encuentra una herramienta compleja, es decir compuesta por dos piezas, en un contexto arqueológico controlado. La primera pieza es una matriz de bronce con improntas en negativo, y la segunda es un bloque de plomo de dimensiones similares al de la matriz que sirve para distribuir la fuerza del golpe en un proceso de estampación. No obstante, la matriz está pensada igualmente para utilizarse en procesos de deformación plástica directos con hilos y láminas de metales nobles. Examinaremos primero la pieza de bronce.

\section{La matriz de bronce}

La llamada matriz de Alcoy es un paralelepípedo de base cuadrangular ligeramente irregular, fabri-

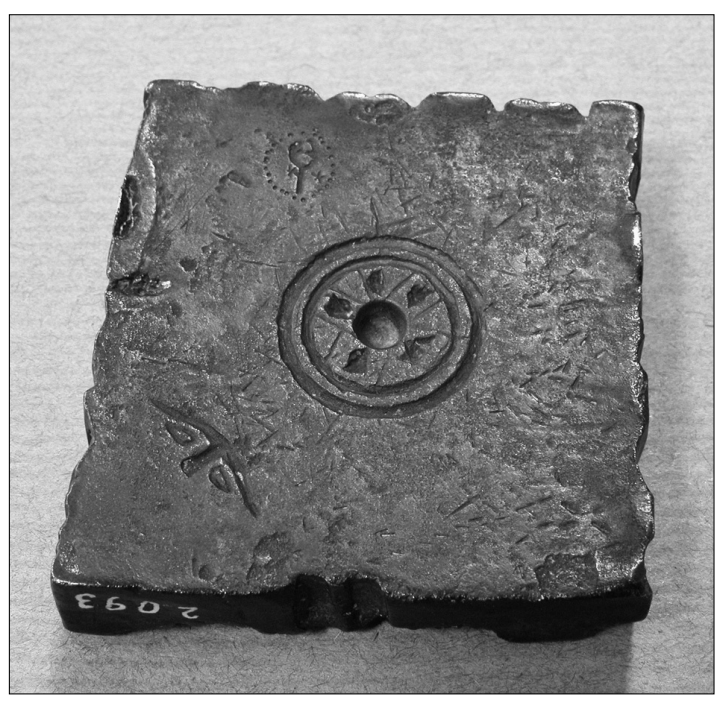

Fig. 19. Cara A de la matriz de bronce.

cado en bronce, que pesa 316,40 grs y mide en torno a los $6 \mathrm{~cm}$ de lado y $1.5 \mathrm{~cm}$ de grosor. Sus seis caras se encuentran trabajadas en hueco con diferentes motivos y formas para trasladar al oro o la plata. Se trata de la parte pasiva y estática, aquella que recibe la fuerza del golpe, de una herramienta especializada en procesos de deformación plástica; la parte activa y móvil se realizaría con herramientas versátiles como martillos, cinceles y punzones de diferentes tamaños y formas, que no se han conservado, utilizadas directamente, o mediante la intermediación del bloque de plomo para distribuir la fuerza y facilitar la estampación en algunos procesos. Actúa, por tanto, como yunque y como matriz, y sobre sus seis caras o mesas de trabajo se pueden transformar hilos, alambres, láminas delgadas y chapas gruesas para fabricar tanto elementos estructurales o partes de joyas, como elementos ornamentales figurados. Es por ello que puede ser mejor definida como una herramienta multiuso.

Es importante la descripción de todas las caras para una mejor comprensión de la herramienta y su utilización. Nombraremos las dos caras de base cuadrangular mediante letras, y con números las cuatro caras rectangulares laterales. Describimos los motivos en hueco a través de su positivado en molde de silicona.

Cara A (Fig. 19): el centro del cuadrado que constituye esta cara está ocupado por un motivo de doble círculo con semiesfera central, que es punto de convergencia para cinco espacios rectangulares e irregulares, delimitados por líneas y ocupados centralmente por un motivo cuadrangular de menor volumen 


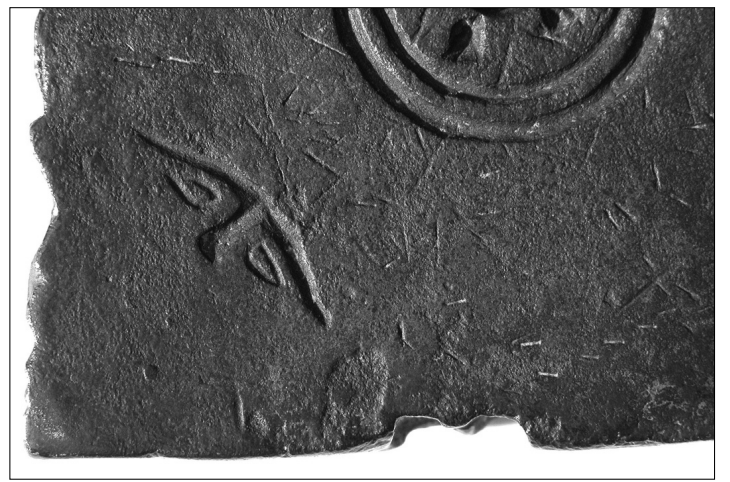

Fig. 20. Detalle de la máscara grabada sobre la Cara A de la matriz de bronce.

que la semiesfera central. Podría describirse como una roseta de rasgos esquemáticos y geometrizados.

Marcando el eje de uno de los ángulos de esta misma cara, aparece un rostro frontal en forma de dos ojos enmarcados por un arco abierto y prolongado que figura las cejas, de cuya parte central surge la nariz (Fig. 20). El trazo es muy superficial, de manera que no creemos se trate de un motivo útil para trasladar al metal, sino de una marca o advocación. Lo mismo ocurre con la figura que aparece en el ángulo contiguo, algo más centrada con respecto al lado del cuadrado, trazada de manera más superficial aún. Se trata en este caso de un círculo de puntos que encierra un motivo trazado a línea en forma de bulbo con prolongación recta que se ha descrito como caduceo (Fig. 21); en el espacio puntillado aparecen dos pequeñas estrellas enmarcando al anterior.

Todos estos motivos ocupan un espacio plano y

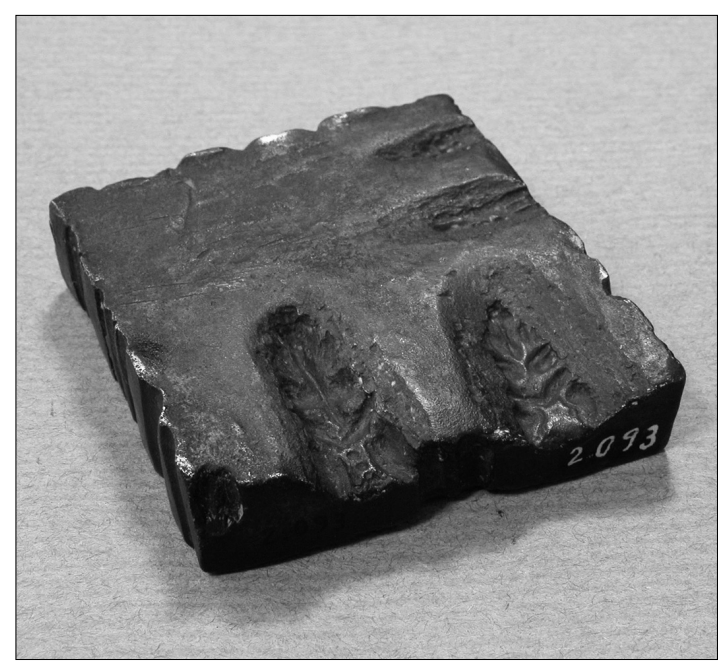

Fig. 22. Cara B de la matriz de bronce.

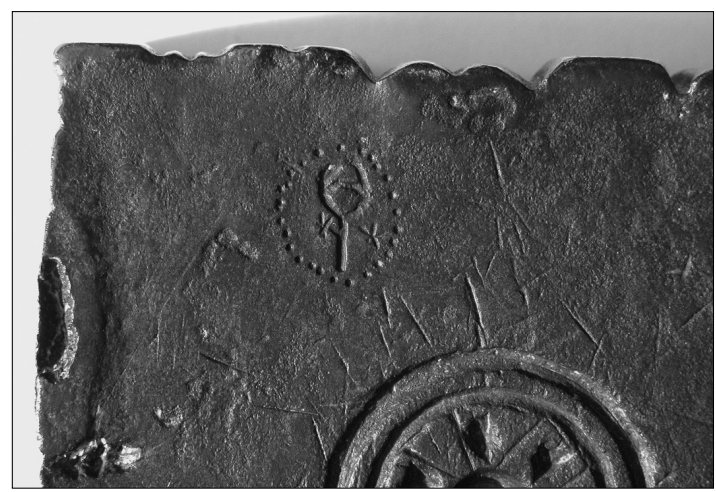

Fig. 21. Detalle del caduceo grabado sobre la Cara A de la matriz de bronce.

liso que presenta multitud de microhuellas fruto del constante golpeteo de diferentes herramientas al trabajar sobre su superficie.

Cara B (Fig. 22): la cara cuadrangular opuesta a la anterior está ocupada por cuatro motivos figurados de la misma naturaleza, transcritos en diferentes tamaños. Se sitúan por parejas, atendiendo al tamaño, en dos lados contiguos del cuadrado, quedando el resto de la superficie metálica sin trabajar. Son cuatro prótomos de lobo que en su momento se describieron como palmetas debido a la dificultad de su identificación al no haber verificado los volúmenes en molde de silicona. En éste se pueden observar los elementos esquematizados de las distintas partes de la cabeza del animal transcritos en secuencia de contigüidad con perspectiva cenital: la línea más sobresaliente y prolongada es la del hocico que marca un eje de simetría en torno al que se alinean los bigotes, los ojos, las cejas formando ángulo, y finalmente las orejas triangulares (Fig. 23). El resultado es un motivo alargado, inorgánico pero muy expresivo, característico de la iconografía ibérica como veremos más adelante.

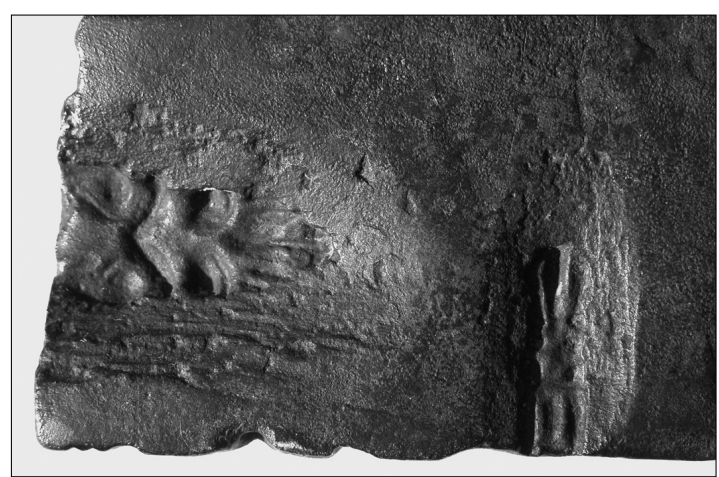

Fig. 23. Detalle de las cabezas de lobo de la Cara B de la matriz de bronce. 

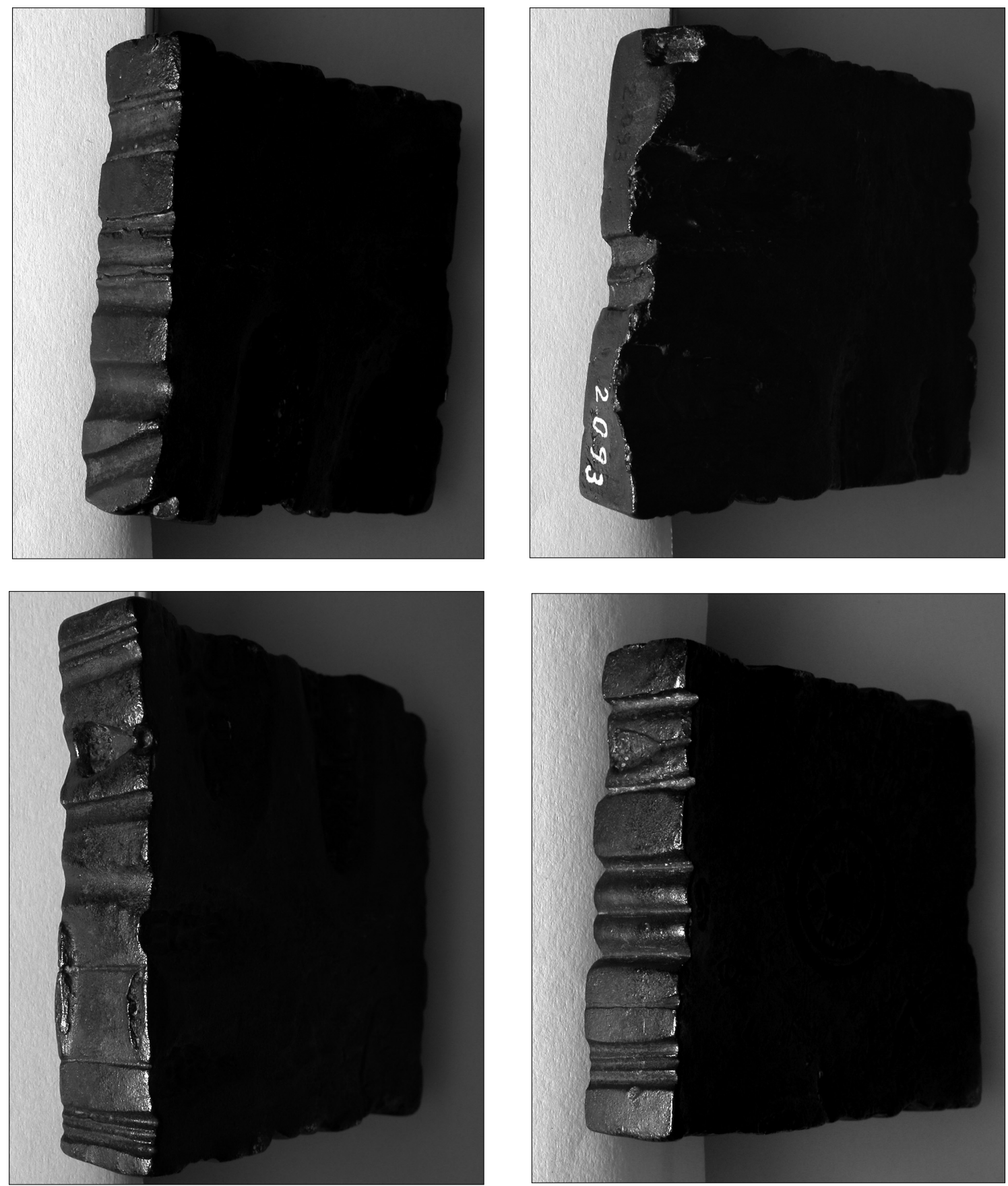

Figs. 24-27: 24. Cara 1 de la matriz de bronce.-25. Cara 2 de la matriz de bronce.-26. Cara 3 de la matriz de bronce.-27. Cara 4 de la matriz de bronce.

Las distintas longitudes de los prótomos, midiendo desde el borde bien delimitado del lado del cuadrado hasta el final del hocico, se agrupan por pares para las magnitudes del centímetro, es decir, la diferencia entre los dos motivos más grandes y los dos más pequeños es al menos del doble; por su parte las diferencias correspondientes a los milímetros se distribuyen linealmente entre los cuatro motivos. Las medidas tomadas son las siguientes: lobo a: $2.6 \mathrm{~cm}$; lobo b: $2.5 \mathrm{~cm}$; lobo c: $1.4 \mathrm{~cm}$; lobo d: $1.3 \mathrm{~cm}$. 
La cuantificación de la anchura es imprecisa debido a las curvaturas y al desgaste producido por el uso. En efecto, la oquedad de cada motivo es relativamente profunda y está delimitada por un área de deformación del metal en forma de halo estratificado; cada estrato corresponde, teóricamente, a una utilización de la herramienta para estampar el motivo correspondiente sobre una gruesa chapa de metal que suponemos era plata. La fuerza necesaria para conseguir trasmitir la forma al metal noble se consigue mediante sucesivos golpes de martillo, un proceso repetido que llegó a deformar notablemente el lado correspondiente a las cabezas de mayor tamaño.

Se podría pensar que sobre estos zoomorfos se pudieron haber estampado finas láminas de oro o plata. No fue así, puesto que en ese caso no se hubiera formado el halo estratificado que va hundiendo cada vez más el motivo en la masa metálica. Estamos seguros de que la matriz se utilizó durante un periodo muy prolongado de tiempo para estampar gruesas chapas de plata como las utilizadas en la fabricación de algunos brazaletes ibéricos, de los denominados acintados, que después señalaremos.

Cara 1 (Fig. 24): el rectángulo que delimita esta cara actúa como un yunque de estrías, es decir, una mesa de trabajo marcada por distintas líneas, estrías y espacios para dar forma a finas láminas de metal noble o a pequeños alambres y cintillas. Los motivos concretos que aparecen son de izquierda a derecha: moldura oblicua; moldura ancha recta; tres molduras contiguas de distinto tamaño; moldura ancha enmarcada por líneas.

Cara 2 (Fig. 25): esta cara está muy deformada porque es la que corresponde al arranque de las cabezas mayores de lobo de la cara B; la oquedad de los motivos zoomorfos y la deformación por trabajado han reducido la superficie útil, un hecho que el orfebre había previsto de antemano porque sólo se marcaron dos molduras paralelas en el espacio central.

Cara 3 (Fig. 26): yunque de estrías y matriz. La secuencia de motivos es la siguiente: tres molduras de tamaños decrecientes muy superficiales; impronta profunda con el volúmen de media bellota con esferilla inferior; dos molduras muy separadas y superficiales; ancho espacio plano separado por dos finas líneas; tres moldurillas finas y superficiales.

Cara 4 (Fig. 27): igual que la cara anterior, se concibió como yunque de estrías y matriz. Todas las estrías que aparecen en esta cara son angulares y relativamente profundas, por contraste con el resto de las caras que hasta ahora se han descrito, que marcan molduras curvas; estas características facilitan el trabajo no sólo de láminas, sino de hilos. La secuencia de motivos es la siguiente: tres molduras iguales juntas; tres molduras separadas por espacios curvos; bellota muy superficial enmarcada por molduras.

El estado de conservación de esta herramienta multiuso es muy bueno, con una pátina homogénea y estable. Los bordes aparecen con melladuras y están suavizados por el desgaste de uso; también hemos observado pequeñas huellas de golpes y ralladuras de distintas herramientas, fácilmente visibles con luz rasante. Por el contrario, según se desprende de la observación de los moldes de silicona, todos los motivos en hueco están perfectamente delimitados y marcados, es decir, la herramienta estaba en perfecto estado de uso cuando se depositó en el departamento F1. El mantenimiento de una herramienta de este tipo implica limpiar las oquedades para dejarlas libres de restos del trabajo anterior y rehacer los motivos que se hayan deformado por el uso, sobre todo en el caso de las cabezas zoomorfas.

Hemos realizado una analítica completa por el método PIXE ${ }^{40}$ para conocer la composición del metal, en una serie diferente de puntos de los que resulta una aleación de base cobre con contenidos en estaño en torno al $10 \%$ y alrededor del $3.5-4 \%$ de plomo. Igualmente realizamos un barrido en la bellota que presenta una huella más profunda para ver si detectábamos restos de algún metal noble; en efecto pudimos medir la existencia de plata que pensamos procede de los restos del material trabajado sobre la herramienta.

\section{El bloque de plomo}

Es un paralelepípedo de dimensiones muy similares al de la matriz, con un peso de 292,93 grs que conserva las improntas de su última utilización (Figs. 28 y 29). En su momento no se identificó como herramienta porque presentaba una inscripción en caracteres ibéricos, y se clasificó como un plomo ibérico inscrito de los habituales ${ }^{41}$.

El plomo es un metal flexible pero inelástico, que funde a muy baja temperatura $\left(327^{\circ} \mathrm{C}\right)$; es muy resistente a la corrosión y a los ataques de determinados ácidos porque se reviste de una capa protectora de

${ }^{40}$ El estudio analítico de la matriz de bronce se llevó a cabo en el Centro de Microanálisis de Materiales de la UAM, Madrid. Agradecemos a su director A. Climent y a M.D. Ynsa todas las facilidades y el conocimiento que pusieron a nuestra disposición. Los resultados completos serán objeto de una próxima publicación más extensa.

${ }^{41}$ Untermann, J. (1990): Monumenta Linguarum Hispanicarum, III. Die Iberischen Inschriften aus Spanien, 2 vols. Wiesbaden, pp. 573-574, G.1.5 


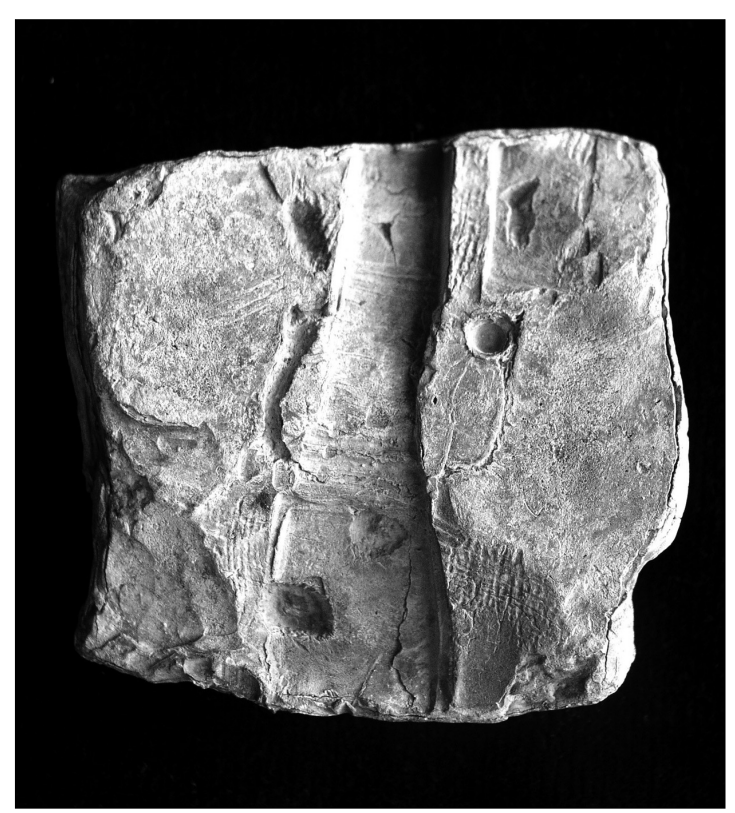

Fig. 28. Anverso del bloque de plomo.

óxido, por todo ello es un metal que desde la prehistoria fue más útil de lo que generalmente se piensa, no sólo aleado con cobre, o sustituyendo al estaño para la producción de bronces llamados plomados, sino en su estado puro, por ejemplo, para la construcción, obras públicas, y en pequeños arreglos caseros, como lañas para los recipientes cerámicos. Su enorme ductilidad y ausencia de oxidación son las cualidades por las que se utilizó también como herramienta pasiva en procesos metalúrgicos como la orfebrería, en combinación con otras herramientas, actuando como apoyo, transmisor o distribuidor de una fuerza aplicada a la conformación de láminas o planchas metálicas. Este es el caso de la matriz y el bloque de plomo encontrados conjuntamente en el departamento F1.

La descripción del proceso concreto de estampación con matriz y bloque de plomo está descrita con todo detalle en el capítulo «De opere quod sigillis imprimitur» del tratado De Diversis Artibus escrito por el monje Teófilo en el siglo $\mathrm{xI}^{42}$. La matriz se sitúa sobre un apoyo firme, con el motivo para estampar en negativo hacia arriba; encima colocamos la lámina metálica, que no debe ser muy gruesa; sobre la lámina disponemos el bloque de plomo y con un martillo pesado golpeamos con fuerza sobre él hasta que el motivo de la matriz queda impreso en la lámina.

El bloque de La Serreta presenta una serie de

${ }^{42}$ Brepohl, E. (1987): Theophilus Presbyter und die mittelalterliche Goldschmiedekunst. Edition Leipzig, pp. 230-232.

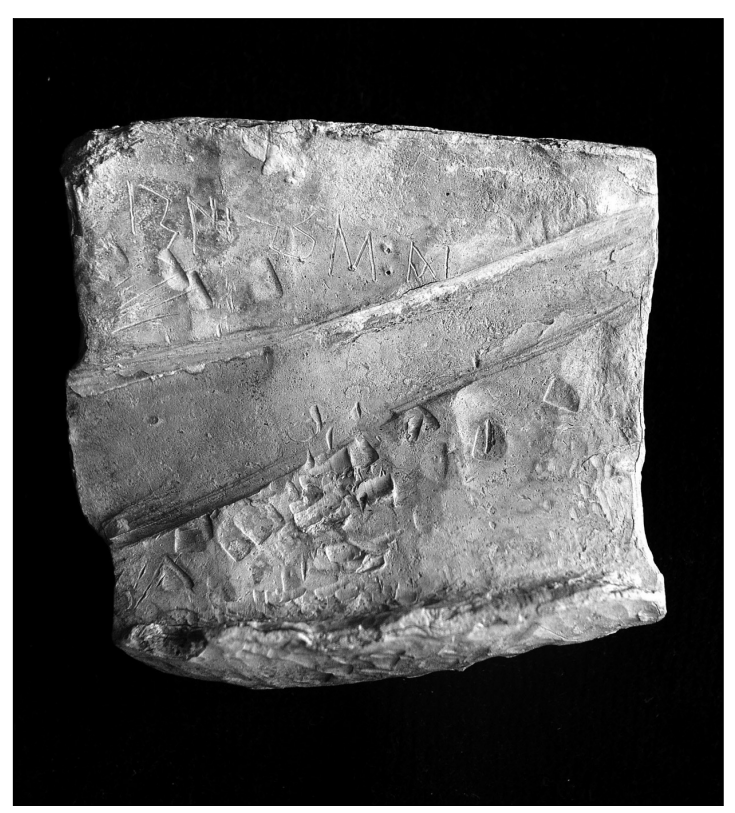

Fig. 29. Reverso del bloque de plomo.

huellas que coinciden con las de uno de los laterales de la matriz. Pensamos que esta técnica indirecta de estampación no se pudo utilizar con las improntas de los prótomos de lobo porque el motivo es demasiado profundo y estaba pensado para estampar chapas excesivamente gruesas para esta técnica en particular, aunque es adecuada para todas las demás.

Otro tipo de huellas que aparecen sobre esta pieza podría indicar la interposición de un fino textil entre la lámina y el bloque (Fig. 28), lo que responde a la necesidad de evitar las manchas que el plomo puede causar al entrar en contacto directo con una lámina de oro, y que después son muy difíciles de eliminar.

Finalmente, sobre la cara opuesta a las huellas hasta ahora comentadas aparecen otras de herramientas, como si se hubieran trabajado láminas metálicas directamente sobre el bloque de plomo, actuando éste como apoyo flexible para un proceso de repujado. Es en esta cara donde en el momento final de su utilización, se grabó la inscripción de caracteres ibéricos (Fig. 29), que aparecen perfectamente impresos, por lo que tenemos que suponer que una vez inscrita, la herramienta no volvió a utilizarse.

\section{Interpretación}

La excepcionalidad de este doble hallazgo no radica únicamente en su naturaleza de herramientas especializadas, sino en la información que contiene 
sobre el conocimiento técnico, la organización artesanal, económica e ideológica en la que se inscribe el orfebre ibérico.

Desde el punto de vista estrictamente funcional, la herramienta multiuso de Alcoy presenta sorprendentes similitudes con el yunque de estrías del depósito francés de Génelard (Saône-et-Loire), del Bronce final, el conjunto de útiles para el trabajo del metal más completo de Europa ${ }^{43}$. Entre otras muchas herramientas para todo tipo de trabajos de deformación plástica, incluía un paralelepípedo de base cuadrangular, en bronce, de dimensiones similares al de Alcoy, cuyas caras menores constituyen mesas de trabajo con distintos tipos de estrías para estampar finas láminas y conformar hilos, probablemente en metales nobles. Las dos caras mayores son lisas y funcionan como simples apoyos para el trabajo. Evidentemente se trata en este caso de una convergencia tecnológica curiosa, sin más significado que la persistencia de una buena solución para un problema técnico; también hay que recordar que el conjunto contenía otros yunques de estrías de formas diversas $\mathrm{y}$ adaptados a las diferentes necesidades del trabajo de metales de base cobre ${ }^{44}$.

En la Península ibérica conocemos, hasta la fecha, sólo dos ejemplos de yunques de estrías y ambos son de pequeño tamaño, concebidos para trabajos de poca envergadura o para el de metales nobles. El primero procede de un depósito del Bronce final de La Mazada (Zamora), y se trata en este caso de una herramienta desechada por fallo de fundición que la rompió en dos trozos. La mesa de trabajo es casi circular y en ella aparecen una serie de estrías paralelas para la deformación de pequeñas láminas o alambres $^{45}$. El segundo ejemplo procede de excavaciones de urgencia en la calle Méndez Núñez de Huelva y data del periodo orientalizante ${ }^{46}$. En este caso la mesa de trabajo es rectangular, dividida en varias zonas con distintos tipos de molduras, además de un motivo de tres círculos formando triángulo.

Estos objetos mencionados ponen de manifiesto

${ }^{43}$ Thevenot, J.P. (1998): «Un outillage de bronzier: le dépôt de la Petite Laugère è Génelard (Saône-et-Loire)», en Mordant, C., Pernot, M. y Rychner, V. (eds.) L'Atelier du Bronzier en Europe du XXe au VIIIe siècle avant notre ère. Paris, pp. 123-144.

${ }^{44}$ Ehrenberg, M.R. (1981): «The anvils of Bronze Age Europe», The Antiquaries Journal, LXI, pp: 14-28.

${ }^{45}$ Armbruster, B., Comendador, B., Montero, I., Perea, A. y Pernot, M. (2003): «Tools and tool marks. Gold and bronze metallurgy in Western Europe during the Bronze and Early Iron Ages», en: Archaeometallurgy in Europe. International Conference. Proceedings, vol. 1. Milan, pp. 255265, especialmente 258-259.

${ }^{46}$ Armbruster, B. et al., (2003) cit. (n. 45), pág. 259. que el yunque de estrías fue una herramienta relativamente extendida entre los artesanos metalúrgicos de toda Europa desde el Bronce final en adelante. Más raro es el hallazgo de matrices con motivos figurados para estampar y ello sólo a partir de la Edad del Hierro. Estos motivos pueden ser de dos tipos, en hueco o en relieve; por ejemplo, sabemos que las placas cuadrangulares que forman parte del cinturón de oro de Aliseda con una escena de lucha heroica entre hombre y león, y otras donde figura un grifo, se estamparon en una matriz ${ }^{47}$; éste sería el ejemplo más antiguo dentro de nuestro territorio peninsular. Las matrices en bronce más conocidas son las que formaban parte del ajuar funerario de la tumba 100 , llamada del orfebre, de la necrópolis ibérica de Cabezo Lucero, en Guardamar del Segura (Alicante). Más de medio centenar de objetos especializados en bronce y hierro, entre las que había una treintena de pequeñas matrices con diversos motivos figurados en relieve, componían un juego de herramientas que incluía un yunque de cubo con mesa de trabajo circular y lisa, muy deformada por el uso ${ }^{48}$.

Una herramienta compleja, compuesta por dos piezas de bronce, es la recuperada recientemente en el yacimiento de Segeda (Calatayud), que en un primer momento se identificó como trefiladora ${ }^{49}$. Podría tratarse más bien de una prensa para estampar o conformar láminas o varillas. Se encontró en el espacio de habitación contiguo a la llamada casa del lagar.

La herramienta de bronce de Alcoy es el único ejemplo que combina en un mismo objeto las funciones de yunque de estrías y matriz en hueco con motivos figurados. La iconografía de los prótomos de lobo es otra de las razones de excepcionalidad. En efecto, procedentes de tesorillos ibéricos de plata $^{50}$ conocemos toda una serie de joyas, anillos y sobre

${ }^{47}$ Perea, A. (1991): Orfebrería Prerromana. Arqueología del Oro. Comunidad de Madrid. Caja de Madrid, pág. 154.

${ }^{48}$ Olcina, M. y Soler J. (1992): Cabezo Lucero. Necrópolis Ibérica (Guardamar del Segura. Alicante). Catálogo Exposición. Museo Arqueológico de Alicante. Alicante. $\mathrm{n}^{\mathrm{o}} 78$ 85; Les Ibères (1997): Catálogo Exposición. Paris-Barcelona-Bonn (1997-1998). Barcelona. $\mathrm{n}^{\circ}$ 71-78. Uroz Rodríguez, H. (2006): El Programa Iconográfico Religioso de la 'Tumba del Orfebre' de Cabezo Lucero (Guardamar del Segura, Alicante), Monografías del Museo de Arte Ibérico de El Cigarralejo, Murcia.

${ }^{49}$ Burillo Mozota, F. (2006): «La ciudad estado de Segeda I», en Burillo Mozota, F. (ed.): Segeda y su contexto histórico. Entre Catón y Nobilior (195 al 153), Homenaje a A. Beltrán Martínez, Zaragoza, pp. 203-240, fig. 30. Arguis Rey, M.L. (2007): El Museo crece: últimos ingresos, Catálogo Exposición, Museo de Zaragoza, pág. 62, fig. 49.

${ }_{50}$ Raddatz, K. (1969): Die Schatzfunde der Iberischen Halbinsel vom Ende des Dritten bis zum Mitte des Ersten Jahrhunderts vor Chr. Geb. Madrider Forschungen, Band 5. Berlin. 
todo brazaletes, que presentan prótomos zoomorfos rematando los extremos abiertos de un aro acintado; las variante son múltiples, y el grado de esquematismo de las cabezas muy diverso, hasta el punto que las identificaciones oscilan entre serpientes, lobos e incluso caballos, variabilidad zoológica que probablemente responda a la realidad, pero que no suscita acuerdos entre los estudiosos actuales. De entre todos los ejemplares, destacamos una pareja de brazaletes procedente del tesorillo de Córdoba, hoy en el Museo Británico ${ }^{51}$, por su semejanza con las que aparecen en la matriz de Alcoy. Evidentemente no se trata de la misma impronta, pero los recursos de la esquematización son los mismos: perspectiva cenital y contigüidad de los elementos anatómicos alineados simétricamente en torno al eje del hocico.

Parece redundante, y por tanto inútil, el hecho de que se hayan trabajado cuatro improntas de cabezas de lobo agrupadas en parejas por tamaños, una el doble que la otra, sin más diferencia aparente. La constatación de las medidas ha puesto de manifiesto que existe un pequeño escalonamiento en los tamaños, en el rango del milímetro, que separan las cuatro improntas. Hemos encontrado un rasgo similar en otra matriz, ya de época romana, con cuatro cabezas de serpiente agrupadas igualmente por parejas, procedente de Alchester (Oxfordshire), hoy en el Ashmolean ${ }^{52}$. Este modo de disponer las improntas no puede responder más que a una razón económica derivada del modo de producción, probablemente orientado hacia un mercado que controlaba los precios de manera muy ajustada, lo que indica el alto grado de mercantilismo que alcanzó la producción orfebre en época ibérica. No debemos olvidar que hacia mediados del siglo IV a.C. los orfebres de la ciudad de Cádiz se regían por un modo de producción altamente desarrollado, con una oferta de productos seleccionados por precios y fabricados en serie $^{53}$.

Otros motivos iconográficos presentes en la matriz son dos bellotas, de diferente tamaño y configuración. El motivo es muy frecuente en la orfebrería ibérica desde época orientalizante hasta la romana, y sería tedioso enumerar los ejemplares conocidos, pero todos ellos están relacionados con objetos que

\footnotetext{
${ }^{51}$ Raddatz, K. (1969) cit. (n. 50): lám. 6.

${ }^{52}$ Henig, M. (1999): «A jeweller's die from Alchester, Oxfordshire», The Antiquaries Journal, LXXIX, pp. 388389.

${ }_{53}$ Perea, A. (2000): «Comportamientos de mercado en la producción orfebre del taller de Cádiz», en Fernández Uriel, P., González Wagner C., López Pardo, F. (eds.) Intercambio y Comercio Preclásico en el Mediterráneo. I Coloquio del Centro de Estudios Fenicios y Púnicos. Madrid, pp. 281-292.
}

hacen alusión a la fecundidad, como las bellotas de la diadema áurea de extremos triangulares de $\mathrm{La}$ Puebla de los Infantes (Sevilla) ${ }^{54}$, o con objetos rituales como los vasos de cuello abocinado de Tivi$\mathrm{sa}^{55}$, conjunto asociado a otros objetos en donde la imagen del lobo es protagonista. Las improntas de Alcoy presentan todos los rasgos de este fruto de manera detallada y naturalista.

La roseta que preside la cara A podría ser una esquematización de la más orgánica orientalizante, pero quizá en este caso deberíamos suponer que el orfebre estaba más interesado en representar un ombligo, la semiesfera central con su significado cosmogónico, que el conocido elemento vegetal. Un esquema similar aparece en un colgante de plata del conjunto de Salvacañete ${ }^{56}$ que reproduce una patera en miniatura con omphalos rodeado de un doble círculo y líneas marcando unos pétalos geometrizados.

En cuanto a lo que hemos considerado marcas o advocaciones, en cualquier caso improntas no funcionales, parecen responder igualmente a ese espíritu mercantilista que se desprende de la propia organización de la herramienta, si aceptamos la interpretación del símbolo encerrado en el círculo puntillado como un caduceo, y los dos ojos como el rostro frontal de una diosa que podría asimilarse a Tanit. No creemos que deban ser leídas como marcas de orfebre, más bien parecen dedicaciones a la divinidad que puede propiciar y proteger el proceso de producción dentro del entramado económico del grupo.

Con respecto al bloque de plomo con inscripción que completa la utilización de la matriz de bronce, tenemos que destacar lo excepcional de su hallazgo, pues si bien se conocen algunos pequeños fragmentos de plomo asociados a herramientas de metalúrgico, nunca se había encontrado un bloque de las dimensiones y características como el que presentamos en esta ocasión. En este sentido, la valoración conjunta del ajuar aparecido en el departamento F1 es determinante para conocer la naturaleza de este extraordinario hallazgo.

\section{LECTURA ICONOGRÁFICA Y ESPACIAL}

La habitación concentra una gran riqueza y variedad de objetos y de elementos iconográficos. Tiene una función de tesaurización, de depósito sacro, don-

\footnotetext{
${ }^{54}$ Perea, A. (2006): «Entre la metáfora y el mito. La representación simbólica de lo femenino en la sociedad ibérica», MARQ Arqueología y Museos, 01, pp. 49-68.

55 Raddatz, K. (1969) cit. (n. 50): lám. 71

${ }^{56}$ Raddatz, K. (1969) cit. (n. 50): lám. 53,1
} 
de aparecen relacionadas cerámicas comunes y piezas extraordinarias. Es insólita la acumulación de imágenes y piezas excepcionales que por sí solas destacan entre el amplio repertorio material de la cultura ibérica y que aparecen concentradas en un sólo departamento de un oppidum, de ahí la importancia incuestionable del espacio. Las piezas acumuladas en la cámara 1 nos llevan a pensar en dos grupos de funciones y prácticas distintas: mostrar y guardar o utilizando una dicotomía en términos mas connotados religiosamente: ostentar y conservar, como estrategia de la memoria que es la tesaurización. Se ostentan, pues, imágenes que transmiten mensajes de carácter no-verbal mediante unos códigos iconográficos compartidos y preciosos, articulados sintácticamente. De forma simultánea se guardan de forma colectiva productos e instrumentos, es decir, se agrupan las bases materiales de la pervivencia del grupo. Ambas funciones aparecen interrelacionadas pues son los mensajes ideológicos los que permiten y avalan la tesaurización. Trataremos de ofrecer algunas lecturas derivadas del análisis contextual y cruzado de los datos disponibles para dotar de sentido al espacio y las prácticas que albergó.

Iniciaremos nuestras reflexiones fijando la atención sobre la acumulación de imágenes. La habitación es un microcosmos espacial que acumula un riquísimo conjunto de elementos que están entre si estrechamente vinculados. Ese conjunto permite una lectura nueva y enriquecedora del espacio.

La plaquita es en sí misma una representación gráfica de ese espacio sacro. Estamos ante un mundo exclusivamente femenino presidido por la figura divina, caracterizada por sus proporciones superiores y por su centralidad en la escena. Ella preside y articula el espacio, se muestra en él. La diosa acoge a los dos lactantes en su seno y a ella se acercan la mujer de la izquierda con otro niño, al que presenta. El grupo de la derecha - de nuevo una mujer y probablemente una niña- realizan un acto cultual a través del diaulós. Es un indicio de la vinculación y aprendizaje de la música en el entorno sacro.

La figura de la auletrís nos enlaza con el Vas dels Guerrers. La figura ritual — muchacha que pertenece a la diosa - nos introduce en el relato mítico del vaso: la iniciación de un joven a través de tres momentos o pasos: la lucha con el monstruo, la caza del ciervo acompañado de un igual, un compañero ya iniciado, a caballo y por último, el certamen heroico, la lucha que lo introduce definitivamente en el mundo de los adultos y le concede el estatus de guerrero ${ }^{57}$.

\footnotetext{
${ }^{57}$ Olmos, R. y Grau Mira, I. cit. (n. 34).
}

Hay pues una prolongación entre la placa votiva y el vaso, a través de una secuencia de edad. El amamantamiento no agota su ámbito de actuación de la diosa. La kourotrophía debe ser larga, no concluye con el don de la leche de la generosa nodriza divina. La Señora se seguirá ocupando de los niños y los jóvenes que parecen con las mujeres en la plaqueta y también del joven protagonista de la historia narrada en el Vas dels Guerrers. Como una presencia invisible o acaso mostrada en su símbolo vegetal que aparece en las escenas que relatan la iniciación modélica del joven. La roseta, que acompaña al joven jinete y al guerrero, es vigor de su rostro y de sus piernas así como del caballo por él cuidado, podría ser una alusión al poder y presencia de la Señora en su territorio. El mensaje parece claro, es la Diosa quien protege y cuida al héroe. Con su participación en la exaltación de los valores heroicos sanciona el poder del elegido y el orden social desigual establecido sobre la base de la superioridad del príncipe.

La naturaleza se erige como escenario de los sucesivos pasos de iniciación. La sobreabundancia y el dinamismo de los elementos vegetales se muestran claramente en los grandes vasos figurados. Y entre ellos aparece el ave, representada en la terracota y el gran kálathos. El ave cumple diversas funciones en el ámbito divino. En la plaqueta acompaña el trono y a la diosa, como en la dama sedente del Cigarralejo y la misma dama de Baza. Cuidan y fecundan su jardín, como vemos en el gran cálato, donde la gran ave pica en las granadas o adormideras. Y anuncian la muerte del ciervo herido en el Vas dels Guerrers, posándose en el lomo del cuadrúpedo. Es una forma de indicar que también el ciervo es posesión divina.

Por último la presencia del lobo, como animal de fronteras. Las flautas de la auletrís con vestido ritual del gran vaso están rematadas con cabecitas de lobo, precisamente casi en contacto con la escena del enfrentamiento del adolescente con la fiera. El mismo instrumento musical nos indica que está configurado así para ritmar una hazaña precisa. El lobo cubrirá la cabeza del ya iniciado en las sucesivas hazañas de este vaso. Pero además la matriz de orfebre repite a diversos tamaños la cabeza frontal del lobo que remata pulseras en plata de los aristócratas. De nuevo un signo de la vinculación de la divinidad y el iniciado.

Apuntemos un segundo aspecto. La terracota es una imagen de grupo, pues la Señora amamanta a dos pequeños y junto a ellos aparecen posiblemente dos madres que presentan sus hijos a la Diosa. Se refuerza la idea de participación múltiple. Es un colectivo que se vinculará con un lazo más allá del 
parentesco, son syntrophoi. Han sido bendecidos el mismo día y han recibido la misma leche de la Dio$\mathrm{sa}^{58}$. Nuevas fórmulas que nos muestran los nuevos lazos que van más allá de los vínculos consanguíneos y que estructuran las formas de agregación social en el oppidum ibérico.

Junto a estas imágenes se conservan otros bienes materiales. Ya nos hemos referido al predominio absoluto de las funciones de almacenamiento y despensa del amplio conjunto de recipientes cerámicos. Ello sugiere que en el departamento F1 se concentraban la producción de un amplio colectivo de campesinos, un grupo suprafamiliar, captada y almacenada al amparo de prácticas religiosas. Quizá se tratase de las primicias y otras porciones de los frutos del campo y del trabajo ofrecidas a la divinidad que preside el lugar. Junto a la producción agrícola envasada en recipientes cerámicos también se guardan los medios de producción, en especial el excepcional instrumento de orfebre y algunas herramientas agrícolas que se mencionan en las notas de excavación pero que hoy no han podido ser reconocidas. Esta misma asociación se encuentra en algunos espacios edetanos y en otros lugares ${ }^{59}$. Ello nos sitúa en la intersección de las prácticas religiosas y socioeconómicas del oppidum. Los aspectos sacros y simbólicos cimientan las relaciones que permiten la vinculación de un grupo social, la captación de excedentes y el control de los medios de producción por parte de los grupos dominantes de la sociedad. Es decir, procesos ideológicos que avalan la formación y consolidación de la sociedad clientelar ibérica definida por A. Ruiz y M. Molinos ${ }^{60}$. En este caso concreto, se trataría de la ubicación de prácticas religiosas de carácter colectivo en una dependencia urbana con una clara función de agregación y vinculación social.

${ }^{58}$ Olmos, R. (2000-2001) cit. (n. 38): pp. 366-367.

${ }^{59}$ En el citado Dep. 14 del Tossal de Sant Miquel de Llíria, Bonet, H. (1995) cit. (n. 6), o en Mas Castellar de El Pontòs, donde se localizan herramientas de hierro junto con otros objetos votivos en el relleno ritual del foso-silo 101. Pons, E. (1997): «Estructures, objectes i fets cultual en el jaciment protohistóric de Mas Castellar (Pontòs, Girona)». Quaderns d'Arqueologia $i$ Prehistòria de Castelló, 18. pp. 71-89.

${ }^{60}$ Ruiz, A. y Molinos, M. (1993): Los iberos. Análisis arqueológico de un proceso histórico. Barcelona. Ruiz Rodríguez, A. (1998): «Los príncipes Iberos. Procesos económicos y sociales», en Aranegui, C. (ed.): Congreso Internacional Los Iberos Príncipes de Occidente (Barcelona, marzo, 1998), pp. 285-300. Barcelona.; Idem, (2000): «El concepto de clientela en la sociedad de los príncipes», en Mata, C. y Pérez, G. (eds.) III Reunió sobre Economia del Món Ibèric. Saguntum-PLAV, extra 3, Valencia, pp. 11-20.
En el contexto social ibérico de esta época se han superado las relaciones consanguíneas propias de la sociedad parental y se deben crear nuevos vínculos identitarios que permitan la construcción del nuevo linaje aristocrático. El fundamento del nuevo modelo social reside en la existencia de un estamento aristocrático que institucionaliza su posición preeminente y un grupo dependiente que se vincula al aristócrata. Cabe por tanto, reforzar los lazos ideológicos que reformulan las relaciones de grupo y sancionan la posición predominante del grupo aristocrático. Y en esas claves de lectura se puede interpretar las imágenes y los mensajes que transmiten.

Las prácticas religiosas dirigen su objetivo hacia el afianzamiento unas fórmulas de relación ciudadanas bajo nuevos vínculos políticos sancionados con prácticas rituales. Es el ámbito de lo sagrado el que arropa los procesos sociales que nos ayudan a entender la articulación suprafamiliar ibérica y la complejidad que adquiere a través de diversos grupos de edad y género. El tema no es nuevo, pues ejemplos semejantes se diseminan en contextos mediterráneos ${ }^{61}$ que nos aportan luz para interpretar los testimonios ibéricos y dan cuenta de la intensidad de las relaciones en ese entorno cultural.

Otras cuestiones y temas de extraordinario interés surgen a medida que profundizamos en el análisis de esta habitación sagrada. Las relaciones entre el artesanado especializado y el ámbito religioso requerirían un estudio pormenorizado. También los aspectos de representación espacial y perspectiva de las imágenes, pues las dos piezas principales se proyectan con esquemas de presentación diferentes: la frontalidad de la plaqueta frente a la circularidad del vaso decorado; una requiere estatismo, el otro movimiento. Por último, la profundización en los temas aludidos de la forma y significado de la iniciación en el mundo ibérico deberán ser objeto de futuros trabajos que aborden esta temática específica. En fin, escogimos algunas claves de lectura entre tantas otras que se acumulan como lo hicieron los preciosos objetos de esta cámara singular.

\footnotetext{
${ }^{61}$ En otros trabajos uno de nosotros ha abordado el tema de la presentación de niños, la nutrición y la tutela de la diosa en ejemplos del Mediterráneo como Locri, Villa Albani o Icaria, Olmos, R. (2000-2001) cit. (n. 38) pp. 367.
}

Recibido el 10-03-08. Aceptado el 15-05-08. 